\title{
On the aerosol weekly cycle spatiotemporal variability over Europe
}

\author{
A. K. Georgoulias and K. A. Kourtidis \\ Laboratory of Atmospheric Pollution and Pollution Control Engineering of Atmospheric Pollutants, Department of \\ Environmental Engineering, Democritus University of Thrace, 67100, Xanthi, Greece
}

Received: 21 December 2010 - Published in Atmos. Chem. Phys. Discuss.: 18 January 2011

Revised: 25 April 2011 - Accepted: 6 May 2011 - Published: 16 May 2011

\begin{abstract}
In this work, we focus on the spatial and temporal variability of the aerosol weekly cycle over Europe as these were recorded from TERRA MODIS and AQUA MODIS satellite instruments. Aerosol optical properties retrieved from MODIS TERRA (February 2000-February 2009) and AQUA (July 2002-December 2008) were used to produce an aerosol weekly cycle index. First, the general aerosol optical depth $\left(\mathrm{AOD}_{550 \mathrm{~nm}}\right)$ weekly patterns were defined at a $1^{\circ} \times 1^{\circ}$ resolution using the satellite-based index and six regions of interest were selected. To remove episodic dust transport events, two different aerosol flags, employing fine mode ratio $\left(\mathrm{FMR}_{550 \mathrm{~nm}}\right)$ and $\mathrm{AOD}_{550 \mathrm{~nm}}$ data, were applied diagnostically, showing that the observed weekly cycles over Europe are due to continental aerosols. A second spatial averaging method was then used for the investigation of the weekly variability and the statistical significance of the weekly cycle over each of the previously selected regions. Three major weekly cycle plumes are observed over Europe. A strong positive (higher values during midweek) weekly cycle plume appears over Central Europe, while a strong negative (higher values during weekend) weekly plume appears over the Iberian Peninsula and the North-eastern Europe. The temporal examination of the weekly cycles shows that in some areas there are seasonal differences in the sign of the weekly cycle. The aerosol weekly variability over different regions in Europe was examined in conjunction with the dominating synoptic wind patterns from the NCEP/NCAR reanalysis, showing that the seasonal weekly cycle plumes over regions situated in the eastern Europe and the Mediterranean Sea could be partly attributed to the westerly transport of continental aerosols.
\end{abstract}

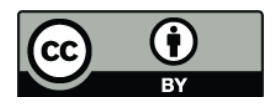

Correspondence to: A. K. Georgoulias (argeor@env.duth.gr)

\section{Introduction}

For decades, scientists investigate the impact of human activities on atmospheric composition, meteorological and climatological parameters. The effect of human activities on these parameters and the complex connections between them cannot always be easily detected. A potent tool for the investigation of the anthropogenic effect on regional pollution, meteorological and climate variables is the identification of weekly cycles in them. Since normally there are no weekly cycles in nature, it becomes obvious that this is a strictly anthropogenic effect caused by the working cycle.

Weekly cycles of photochemical parameters, ozone, primary pollutants such as $\mathrm{NO}_{\mathrm{x}}, \mathrm{CO}$ and aerosols were observed from mid $70 \mathrm{~s}$ in several urban centers (e.g. New York; Washington, DC; Los Angeles) in the US (Cleveland et al., 1974; Lonneman et al., 1974; Lebron, 1975; Elkus and Wilson, 1977) with the idea of considering weekday-weekend variations in pollution dating back to the late works of Ashworth (1929), Ashworth (1933) and Haagen-Smit and Brunelle (1958). The years that followed, many studies particularly in America and Europe (Cleveland and McRae, 1978; Karl, 1978; Bower et al., 1989; Altshuler et al., 1995; Pryor and Steyn, 1995; Brönnimann and Neu, 1997; Vukovich, 2000; Pont and Fontan, 2001; Marr and Harley, 2002; Heuss et al., 2003; Paschalidou and Kassomenos, 2004; Shutters and Balling, 2006; Murphy et al., 2007; Stephens et al., 2008; Schipa et al., 2009) have shown that in urban areas ozone concentrations generally maximize on the weekend when emissions of $\mathrm{NO}_{\mathrm{x}}$ and volatile organic compounds (VOCs) are lowest due to decreased vehicle emissions, while in rural areas or areas with high biogenic VOC emissions ozone may minimize on the weekend. The aerosol concentration weekend effect has also been examined for sites situated in central and north America (Stephens et al., 2008; Murphy et al., 2008), Europe (Barmet et al., 2009) and Asia (Gong et al., 2007; Choi et al., 2008; Kim et al., 2009). The majority

Published by Copernicus Publications on behalf of the European Geosciences Union. 
of the studies on aerosol concentration weekly cycles have focused on urban sites suggesting lower values during weekends and higher during workdays, which is more or less expected due to decreased industrial activity and commuter traffic during weekends. However, a work from Murphy et al. (2008), where measurements from both urban and rural stations around the US were used, suggested that the aerosol concentration weekly cycles are unlikely to be from local sources at the sampling sites only.

Today, there is evidence that the aerosol weekly cycle is not a local issue restricted to the ground level but it can extend over larger geographical areas in the troposphere and hence be detectable not only from ground but also from satellite-based instruments. Jin et al. (2005) using summer aerosol optical depth (AOD) measurements from the Aerosol Robotic Network (AERONET) detected a weekly variability of the columnar aerosol load over New York. Bäumer et al. (2008) using AERONET AOD $440 \mathrm{~nm}$ measurements from 14 stations in central Europe found a significant weekly cycle for 12 of them with a mean difference between minimum and maximum of $\sim 20 \%$ for stations in Germany and the greater Paris area and $\sim 10 \%$ for stations in northern Italy and Switzerland. Beirle et al. (2003) initiated the effort of detecting pollution weekly cycles from space using total $\mathrm{NO}_{2}$ measurements from Global Ozone Monitoring Experiment (GOME) instrument aboard ERS-2. They found a Sunday minimum with reduced $\mathrm{NO}_{2}$ tropospheric columns of $\sim 25-50 \%$ for the US, Europe and Japan. No weekly cycle was observed over China while for Middle East, Friday or Saturday (for Israel), was the day of minimum, indicative of the cultural and religious differences between these regions. Xia et al. (2008) examined the weekly cycle of the $\mathrm{AOD}_{550 \mathrm{~nm}}$ using satellite observations from Moderate Resolution Imaging Spectroradiometer aboard EOS TERRA (MODIS TERRA) in conjunction with ground-based data from the AERONET. The 6-year averages show a statistically significant weekly cycle in different regions around the globe (Europe and the US). An inverse phase of the weekly cycle was observed for eastern China which is in contrast with ground level observations (Gong et al., 2007). In a very recent work, Quaas et al. (2009) presented spatially averaged results using satellite observations from MODIS and data from two global climate models. They found clear aerosol weekly cycles in the data above Europe while the model runs indicated that the differences in emissions between weekdays and weekends may lead to such a cycle. In parallel with ozone, aerosols and the other atmospheric pollutants, there are many studies investigating the anthropogenic influence on weekly cycles in several meteorological parameters. These include rainfall amount and frequency, surface temperature, diurnal temperature range, precipitation, wind speed, etc. (e.g. Gordon, 1994; Simmonds and Keay, 1997; Cerveny and Balling Jr., 1998; Forster and Solomon, 2003; Jin et al., 2005; Bäumer and Vogel, 2007; Gong et al., 2007; Bell et al., 2008; Sanchez-Lorenzo et al., 2008; Laux and Kunst- mann, 2008; Kim et al., 2009, 2010; Sitnov, 2010). However, especially for precipitation, the existence of a statistically significant weekly cycle has been challenged and further discussed in a significant number of studies (e.g. DeLisi et al., 2001; Schultz et al., 2007 and references therein; Hendricks Franssen, 2008; Bäumer and Vogel, 2008; Hendricks Franssen et al., 2009; Sanchez-Lorenzo et al., 2009).

In this work, we have focused on the spatial and temporal variability of the aerosol weekly cycle over Europe $\left(30^{\circ} \mathrm{N}-\right.$ $70^{\circ} \mathrm{N}, 15^{\circ} \mathrm{W}-60^{\circ} \mathrm{E}$ ) as this was recorded from MODIS TERRA and AQUA satellite instruments. Aerosol optical properties retrieved from TERRA and AQUA MODIS were used in order to produce an aerosol weekly cycle index. This method was initially proposed by Xia et al. (2008); however, as will be shown here, the method has limitations which should be taken into account. The general weekly patterns were defined with the use of the satellite-based index and 6 regions of interest were selected. A second method was used for the investigation of the weekly variability and the statistical significance of the weekly cycle over the selected regions. This method was originally applied by Quaas et al. (2009) on MODIS and modeled aerosol data for a broad area including central Europe. Here, it is shown that this kind of analysis returns better results when applied for smaller regions with uniform weekly spatial patterns. The weekly cycle was also examined on a seasonal basis and the different aerosol weekly variability over different regions in Europe was examined in conjunction with the dominating synoptic wind patterns.

\section{Data and methods}

\subsection{Data}

The satellite data used here are part of the level-3 MODIS TERRA (MOD08_D3) and MODIS AQUA (MYD08_D3) $1^{\circ} \times 1^{\circ}$ daily gridded Collection 005 dataset. The data have been acquired through LAADS (Level 1 and Atmosphere Archive and Distribution System) (http://ladsweb.nascom. nasa.gov). MODIS TERRA was launched on board the Terra satellite on 18 December 1999, with daytime equator crossing at 10:30 LT and MODIS AQUA was launched on board the AQUA satellite on 4 May 2002, with daytime equator crossing at 13:30LT. MODIS with a viewing swath of $2330 \mathrm{~km}$ provides almost daily global coverage. MODIS measures backscattered radiation at 36 spectral bands between 0.415 and $14.235 \mu \mathrm{m}$ with a spatial resolution of 250,500 and $1000 \mathrm{~m}$. Two separate algorithms, one for land (Kaufman et al., 1997; Levy et al., 2007a, b; Remer et al., 2005) and one for ocean (Tanré et al., 1997; Levy et al., 2003; Remer et al., 2005) are used for the retrieval of aerosol optical properties. MODIS aerosol properties from different collections have been consequently validated against AERONET Sun photometer measurements (e.g. Chu et al., 2002; Remer et al., 2002, 2005; Levy et al., 2010). The pre-launch uncertainty of the MODIS aerosol 
optical depth $(\tau)$ is $\pm 0.05 \pm 0.2 \tau$ over land (Chu et al., 2002), and $\pm 0.03 \pm 0.05 \tau$ over ocean (Remer et al., 2002). The pre-launch uncertainty of the fraction of fine mode to total aerosol optical depth or else fine mode ratio is $\pm 30 \%$ over oceans (Remer et al., 2005).

In this work, the aerosol optical depth at the wavelength of $550 \mathrm{~nm}$ over land and ocean $\left(\mathrm{AOD}_{550}\right)$ (Optical_Depth_Land_And_Ocean_Mean) and the fraction of fine mode to total aerosol optical depth or else fine mode ratio $\left(\mathrm{FMR}_{550}\right)$ (Optical_Depth_Ratio_Small_Land_And_Ocean_Mean) over both land and ocean from Collection 005 were used. In general, FMR 550 over ocean is rather trustful; however, over land it can only give an indication of the type of aerosols (dust/non-dust) being more a qualitative rather than a quantitative measure (L. Remer, personal communication, 2010). The analyzed datasets span from February 2000 to February 2009 for TERRA and from July 2002 to December 2008 for AQUA MODIS. The region under investigation is the greater European area $\left(30^{\circ} \mathrm{N}-70^{\circ} \mathrm{N}, 15^{\circ} \mathrm{W}-60^{\circ} \mathrm{E}\right)$ which is represented in $30001^{\circ} \times 1^{\circ}$ geographical cells.

Daily mean, wind speed and direction at the $850 \mathrm{mbar}$ pressure level for the period 2000-2009 were obtained from National Center for Environmental Prediction/National Center for Atmospheric Research (NCEP/NCAR) Reanalysis data. The NCEP/NCAR Reanalysis contains global meteorological conditions with a $2.5^{\circ}$ horizontal resolution and a 17 level vertical resolution at $6 \mathrm{~h}$ time intervals (Kalnay et al., 1996; Kistler et al., 2001). The reanalysis dataset captures synoptic scale dynamic features, thus being suitable for the investigation of large scale aerosol transport patterns.

\subsection{Data analysis}

A set of previously used methods was implemented in order to obtain a balance between the detection of the spatial and temporal variability of weekly cycles and the statistical significance of our results. For the detection of the weekly patterns a method similar to Xia et al. (2008) was followed. Calculations were made for each grid cell separately. This method was applied on the $\mathrm{AOD}_{550}$ dataset and two new datasets emerged from the initial one. For each grid cell $i$, a daily value $\left(d_{i j m y, \text { new }}\right)$ corresponding to day $j$ (MondaySunday) of week $m$ and year $y$ is expressed as a percentage departure $(\%)$ of the initial daily values $\left(d_{i j m y, \text { old }}\right)$ from the weekly average ( wa $_{\text {imy }}$ ) using the equation presented below:

$d_{i j m y, \text { new }}=100\left(d_{i j m y, \text { old }}-\right.$ wa $\left._{i m y}\right) /$ wa $_{\text {imy }}$

where $j=1-7$ and $m=1-52$ (or 53 depending on the year). The $d_{i j m y, \text { new }}$ values were afterwards averaged for each day of the week separately and this way the average percent departure (APD) of each day of the week from the weekly average (7 values for each cell $i$, one for each day of the week from Monday to Sunday) for the whole period of interest was calculated. For the investigation of the general weekly patterns a second dataset was compiled. For each grid cell $i$ there is one value $w_{\text {imy }}$ for each week $m$ of year $y$ corresponding to the percentage of the difference between the average value of the initial dataset for Wednesday-Friday and the average value for Saturday-Monday to the weekly average wa imy $_{\text {. }}$

$$
\begin{aligned}
w_{\text {imy }}= & 100\left(\underset{j=\text { Wed-Fri }}{\text { average }}\left(d_{i j m y, \text { old }}\right)-\underset{j=\text { Sat-Mon }}{\text { average }}\left(d_{i j m y, \text { old }}\right)\right)(2) \\
& / w a_{\text {imy }}
\end{aligned}
$$

By averaging the $w_{\text {imy }}$ values for the whole period of interest one obtains the mean percentage of the difference between midweek and weekend to the weekly average for each grid cell, hereafter denoted as Weekly Cycle Index (WCI). Three-day averages were chosen instead of two-day in order to obtain more robust statistics. Only weeks that have at least two days of data with at least one day of data being among Wednesday-Friday and at least one being among SaturdayMonday were used in both datasets. The aforementioned sampling methods render systematic weekly cycles more evident, similar to the diurnal analysis of Smirnov et al. (2002), since the values are normalized with the special characteristics of each week. A two tailed t-test was used in order to examine whether the APD and WCI values are statistically different from zero. Statistical significance is indicated only when it exceeds the $90 \%$ confidence level. However, the inclusion of small negative optical depth values $(\geq-0.05)$ in Collection 005 (Remer et al., 2006; Levy et al., 2009) could lead to false results when using WCI to examine the weekly cycle patterns. For places with very low aerosol load where small negative and positive values appear in the same week, the weekly means could be zero or very close to zero while the weekday-weekend difference on the other hand could be significantly different than zero. Since the calculation of WCI includes normalization of weekday-weekend differences $w_{\text {imy }}$ with the weekly mean wa imy $_{\text {, }}$, those zero values could lead to huge, negative or positive, individual values which in turn could give false patterns. Several tests have been applied in order to detect anomalously high or low $w_{\text {imy }}$ values. The limit of $\pm 1000 \%$ was set to $w_{\text {imy }}$ which proved to be helpful in "clearing" the WCI patterns.

Despite the fact that fine mode ratio $\left(\mathrm{FMR}_{550}\right)$ expresses more a dust/non-dust flag usually taking values 0 or 1 over land (Remer et al., 2005) rather than the ratio of $\mathrm{AOD}_{550}$ dedicated to fine mode aerosols as it does over oceans, the aerosol type flag originally suggested by Barnaba and Gobbi (2004) and hereafter denoted as (flag1) may be used for the identification of cases were dust is the dominating aerosol type, thus eliminating the effect of episodic aerosol transport (e.g from Sahara) on the signal of the weekly cycle. In cases with $\mathrm{AOD}_{550} \geq 0.3$ and $0 \leq \mathrm{FMR}_{550} \leq 0.7$ the dominant aerosol type is dust. A quite similar but less strict flag (including mixed type aerosols) previously used by Kaskaoutis et al. (2007) was also used (flag2). Here, in 
cases with $\mathrm{AOD}_{550} \geq 0.3$ and $0 \leq \mathrm{FMR}_{550} \leq 0.6$ the dominant aerosol type is classified as dust. The two aerosol flags were used diagnostically for the investigation of the continental character of the weekly cycle over different regions.

After the recognition of the general weekly patterns, box regions with different weekly cycle characteristics were selected in order to generalize our results. Mean values of APD and WCI for each of the box regions were calculated from the corresponding grid results following the formula presented below:

Mean $=\left(\sum \mathrm{obs}_{i} \operatorname{mean}_{i}\right) /\left(\sum \mathrm{obs}_{i}\right)$

where obs $i_{i}$ is the number of observations used for the calculation of mean $_{i}$ for each grid cell $i$.

After the definition of the regions of interest we followed a method previously presented by Quaas et al. (2009) for the investigation of the statistical significance of the weekly cycles. However, we argue later that this method, should be used only after regions of interest have been identified and not for very large areas. A third dataset consisting of daily area averages for each of the 6 selected regions was created. A total of 12 time series (6 for TERRA and 6 for AQUA) with daily area averages were analyzed separately. The APD of each day of the week from the weekly mean (a total of 7 values, one for each day of the week from Monday to Sunday) was calculated for each of the time series using the method outlined previously (Eq. 1). Again, only weeks with at least one day being among Wednesday-Friday and at least one being among Saturday-Monday were used. The same procedure was repeated for hypothetical 6-day and 8day weeks. The 6 and 8-day weekly cycle was compared to the 7-day cycle to examine whether the signal (difference between the day of maximum and minimum APD) in the later case is stronger or not. This gives an indication of the significance of the 7-day cycle. However, as it was discussed in Choi et al. (2008), except from the fact that the time series are influenced by the synoptic weather noise on approximately a few days to 14 days (a period that includes the 7-day cycle), the 7-day cycle may fluctuate by 1 or 2 days due to contamination from secondary aerosol formation and/or aerosol loading. According to this, the existence of a 7-day signal much stronger than the 6 and 8-day signal is an indication of a statistically significant local weekly cycle. On the contrary, the existence of a clear 7-day signal comparable to the 6 and 8-day signal does not necessarily undermine the statistical significance of the weekly cycle but it could be an indication of a synoptically driven weekly cycle due to transport of aerosols from other regions.

In addition, the discrete Fourier transform $X$ of the time series was calculated by using the Fast Fourier Transform (FFT) algorithm. Despite the fact that the time series emerged after spatially averaging over much larger areas than a single $1^{\circ} \times 1^{\circ}$ grid cell there were still days with no measurements. Like in previous studies (Hies et al., 2000;
Marr and Harley, 2002), before applying the FFT, logarithmic transformation for variance stabilization was applied on the original time series. Linear detrending was applied and the average $\log$ concentration was extracted from all values to obtain a zero mean for the series. The missing values were set to zero. 12 new time series emerged and subsequently the periodogram was calculated using the following formula:

$\Phi\left(v_{k}\right)=|X(k)|^{2}=\left|\frac{1}{N}\left(\sum_{t=0}^{N-1} x_{t} \exp \left\{-2 \pi i v_{k} t\right\}\right)\right|^{2}$

where $\Phi\left(v_{k}\right)$ is the squared amplitude of $X$ (i.e. the spectral density), $k=0,1, \ldots, N-1$ with $N$ being the number of the observations, $x_{t}$ the new time series and $v_{k}=k / N$. The periodogram indicates the strength of the signal as a function of frequency and its spectra over the frequency range corresponds to the variance of the time series data. However, the periodogram is known to be a poor estimator of the spectrum and therefore requires some form of spectral window smoothing. A three-point Hanning window was applied three successive times for smoothing and 8 degrees of freedom were obtained (see Weedon, 2005). The existence of a spectral peak at a frequency equal to $1 / 7$ days $^{-1}$ is a strong indication of a 7-day cycle. The statistical significance of a seven day period is investigated through a red noise fit using a first-order autoregressive model AR(1) (Mann and Lees, 1996; Weedon, 2005; Wilks, 2006). A red noise background spectrum was used because geophysical time series tend to have larger power at lower frequencies (Ghil et al., 2002). The red noise spectrum is calculated from the lag-one autocorrelation coefficient of the time series and the average value of the power spectrum using Eq. (4) from Mann and Lees (1996). The significance of the spectral peaks can be estimated assuming that the uncertainties of the spectral estimates follow a chi-squared distribution (Priestley, 1981; Percival and Walden, 1993). The spectral confidence intervals are calculated using Eq. (8.79) from Wilks (2006) from the degrees of freedom of the estimates (here 8) divided by the $\chi^{2}$ value appropriate to the confidence interval required (here $90 \%$ or $95 \%$ ). When a spectral peak exceeds the corresponding interval then statistical significance is indicated.

The seasonal WCI patterns were also examined defining four seasons, December-January-February (DJF), MarchApril-May (MAM), June-July-August (JJA) and SeptemberOctober-November (SON) which are typical for the midlatitudes. The seasonal weekly variability was examined for the 6 box regions using the APD values calculated from the MODIS TERRA and AQUA time series. The seasonal variability of aerosols is examined in conjunction with daily mean synoptic wind speed and direction for the $850 \mathrm{mbar}$ pressure level data from the NCEP/NCAR reanalysis dataset. It is proposed here that aerosol weekly cycles could be transferred away from areas with strong and dominating weekly patterns, affecting the regional weekly patterns over areas with no or weak local weekly variability. 
a)

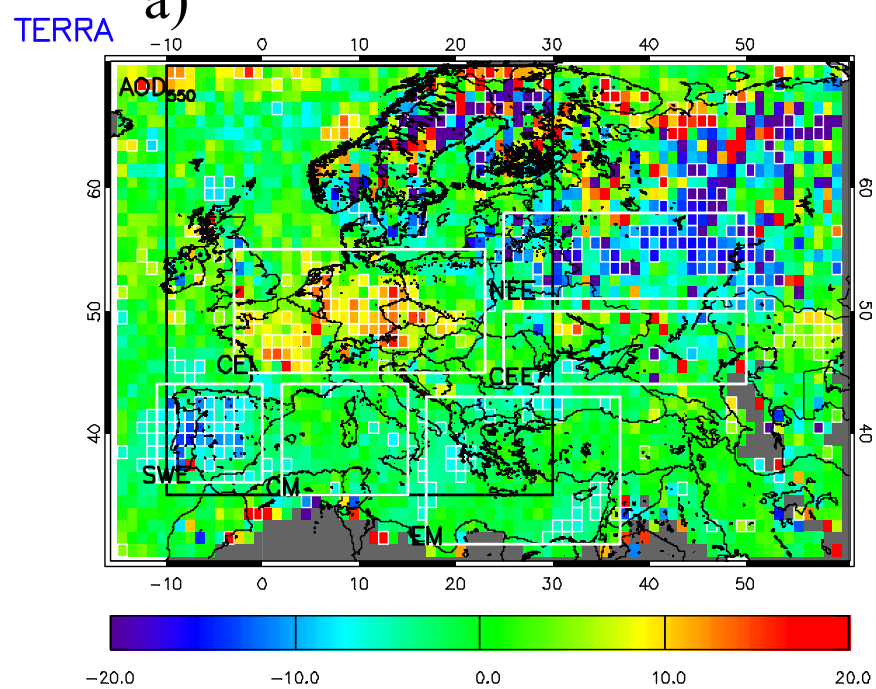

b)

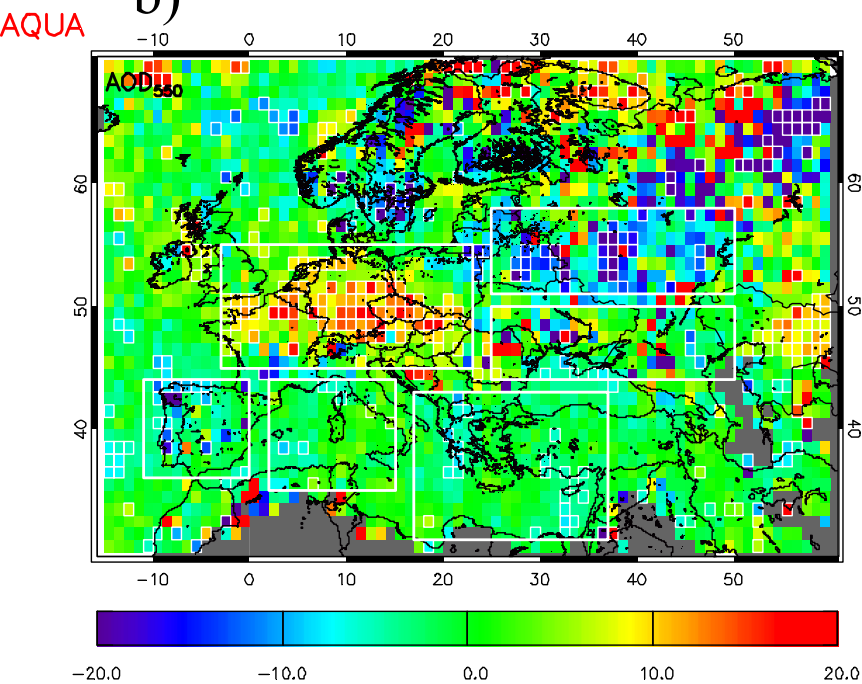

d)
TERRA C)

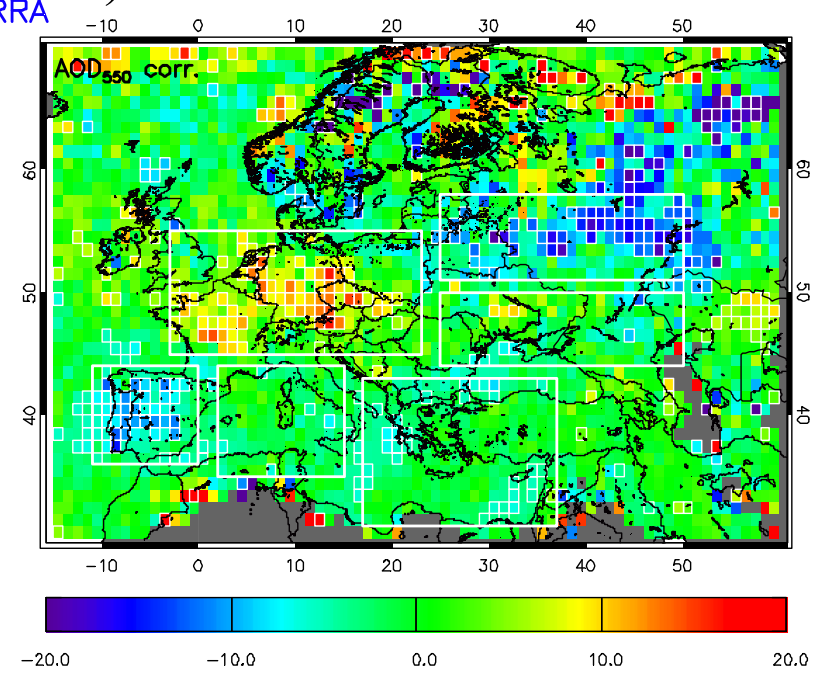

AQUA

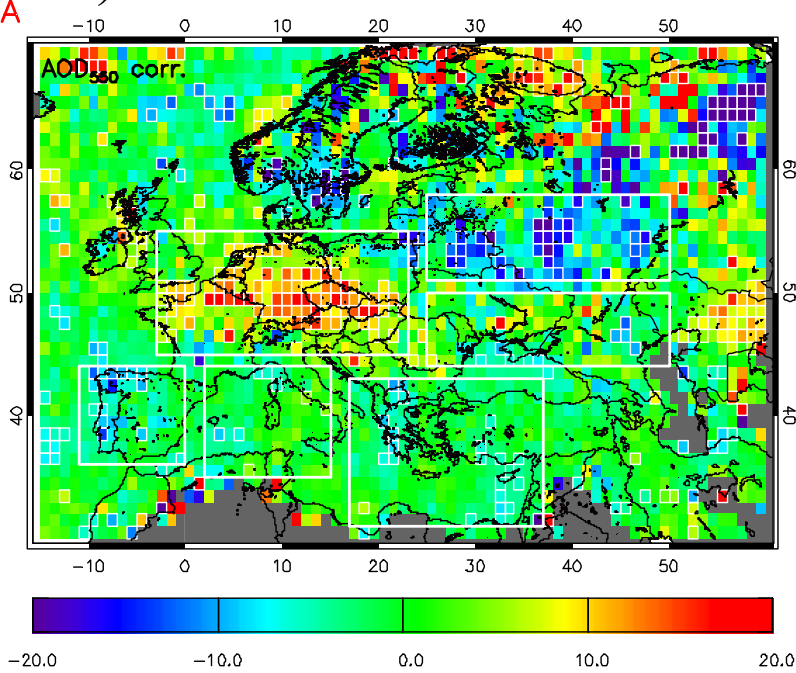

Fig. 1. Left column: From TERRA MODIS data for the period February 2000-February 2009. Right column: AQUA MODIS data for the period July 2002-December 2008. (a, b) WCI patterns calculated from AOD 550 measurements, (c, d) the same as (a, b) but for data corrected with the $\pm 1000 \%$ limit. The grid cells with a statistically significant value at the $90 \%$ confidence level according to the two tailed t-test appear with a thin white outline. The six regions of interest are marked with a thick white outline in all the maps. The region examined in Quaas et al. (2009) (QE) is marked with a thick black line in Fig. 1a only. See also text.

\section{Results and discussion}

\subsection{Detection of aerosol weekly patterns}

The calculation of WCI for MODIS TERRA and AQUA for the period February 2000-February 2009 and July 2002December 2008, respectively, revealed quite similar spatial patterns for the weekly cycle of aerosols across Europe (see Fig. 1a, b). 6 regions with different characteristics were studied in more detail. The 6 regions are marked with a thick white outline in all the maps appearing in this paper. In Fig. 1a the region examined in Quaas et al. (2009) (QE) is also marked with a thick black line. It is quite obvious that this greater region encircles regions with differing weekly cycles. The grid cells with a statistically significant weekly cycle at the $90 \%$ confidence level according to the two tailed t-test appear with a thin white outline. Central Europe (CE) is characterised by a clear positive cycle with higher values during midweek than during weekend. The positive weekly plume extends from western France to Poland and from northern Italy to northern Germany. A clear negative cycle appears over the box regions surrounding South-western Europe (SWE) which covers almost the whole Iberian Peninsula 
Table 1. Regions of interest defined from the WCI with their corresponding geolocation, the average WCI per region for the initial dataset, for the corrected dataset using the $\pm 1000 \%$ limit and for the corrected dataset using the $\pm 1000 \%$ limit and additional corrections using flag1 and flag2. The statistical significance at the $90 \%$ confidence level and the number of values included in the calculations are also given.

\begin{tabular}{|c|c|c|c|c|c|c|c|}
\hline Region & Geolocation & $\begin{array}{r}\text { (TERRA) } \\
\text { WCI/WCI corr. (\%) } \\
\text { WCI corr. \& flag } 1 / 2\end{array}$ & $\begin{array}{r}\text { (TERRA) } \\
\text { Signif. } 90 \%\end{array}$ & $\begin{array}{r}\text { (TERRA) } \\
\text { Values } \\
\text { WCI corr. \& flag } 1 / 2\end{array}$ & $\begin{array}{r}\text { (AQUA) } \\
\text { WCI/WCI corr. }(\%)\end{array}$ & $\begin{array}{r}\text { (AQUA) } \\
\text { Signif. } 90 \%\end{array}$ & $\begin{array}{r}\text { (AQUA) } \\
\text { Values }\end{array}$ \\
\hline Q09 EUROPE (QE) & $\left(35^{\circ} \mathrm{N}-70^{\circ} \mathrm{N}, 10^{\circ} \mathrm{W}-30^{\circ} \mathrm{E}\right)$ & $\begin{array}{r}-0.80 /-0.58 \\
+0.33 / 0.21\end{array}$ & $\begin{array}{l}\text { Yes/yes } \\
\text { Yes/yes }\end{array}$ & $\begin{array}{l}391469 / 391352 \\
354852 / 359811\end{array}$ & $\begin{array}{r}-0.23 /-0.07 \\
+0.53 /+0.40\end{array}$ & $\begin{array}{r}\text { No/no } \\
\text { Yes/yes }\end{array}$ & $\begin{array}{l}277522 / 277418 \\
255849 / 259122\end{array}$ \\
\hline Central Europe (CE) & $\left(45^{\circ} \mathrm{N}-55^{\circ} \mathrm{N}, 3^{\circ} \mathrm{W}-23^{\circ} \mathrm{E}\right)$ & $\begin{array}{l}+4.28 /+4.13 \\
+4.06 /+4.06\end{array}$ & $\begin{array}{l}\text { Yes/yes } \\
\text { Yes/yes }\end{array}$ & $\begin{array}{l}65158 / 65146 \\
57027 / 58181\end{array}$ & $\begin{array}{l}+5.56 /+5.60 \\
+5.11 /+5.20\end{array}$ & $\begin{array}{l}\text { Yes/yes } \\
\text { Yes/yes }\end{array}$ & $\begin{array}{l}44693 / 44681 \\
40187 / 40968\end{array}$ \\
\hline South-western Europe (SWE) & $\left(36^{\circ} \mathrm{N}-44^{\circ} \mathrm{N}, 11^{\circ} \mathrm{W}-0^{\circ} \mathrm{E}\right)$ & $\begin{array}{l}-5.58 /-5.71 \\
-3.53 /-3.55\end{array}$ & $\begin{array}{l}\text { Yes/yes } \\
\text { Yes/yes }\end{array}$ & $\begin{array}{l}36169 / 36158 \\
33162 / 33394\end{array}$ & $\begin{array}{l}-4.81 /-3.87 \\
-1.19 /-1.45\end{array}$ & $\begin{array}{l}\text { Yes/yes } \\
\text { Yes/yes }\end{array}$ & $\begin{array}{l}25827 / 25802 \\
23925 / 24066\end{array}$ \\
\hline North-eastern Europe (NEE) & $\left(51^{\circ} \mathrm{N}-58^{\circ} \mathrm{N}, 25^{\circ} \mathrm{E}-50^{\circ} \mathrm{E}\right)$ & $\begin{array}{l}-9.17 /-6.98 \\
-6.68 /-6.87\end{array}$ & $\begin{array}{l}\text { Yes/yes } \\
\text { Yes/yes }\end{array}$ & $\begin{array}{l}34663 / 34625 \\
32636 / 32893\end{array}$ & $\begin{array}{l}-6.56 /-6.88 \\
-6.88 /-6.86\end{array}$ & $\begin{array}{l}\text { Yes/yes } \\
\text { Yes/yes }\end{array}$ & $\begin{array}{l}23730 / 23697 \\
22799 / 22934\end{array}$ \\
\hline Central Mediterranean (CM) & $\left(35^{\circ} \mathrm{N}-44^{\circ} \mathrm{N}, 2^{\circ} \mathrm{E}-15^{\circ} \mathrm{E}\right)$ & $\begin{array}{r}-1.28 /-1.28 \\
+0.57 /+0.45\end{array}$ & $\begin{array}{l}\text { Yes/yes } \\
\text { Yes/yes }\end{array}$ & $\begin{array}{l}50386 / 50386 \\
43711 / 44418\end{array}$ & $\begin{array}{r}-0.48 /-0.53 \\
+0.34 /+0.28\end{array}$ & $\begin{array}{r}\text { No/yes } \\
\text { No/no }\end{array}$ & $\begin{array}{l}36191 / 36190 \\
31771 / 32195\end{array}$ \\
\hline Eastern Mediterranean (EM) & $\left(31^{\circ} \mathrm{N}-43^{\circ} \mathrm{N}, 17^{\circ} \mathrm{E}-37^{\circ} \mathrm{E}\right)$ & $\begin{array}{l}-1.87 /-1.86 \\
+0.06 /-0.06\end{array}$ & $\begin{array}{r}\text { Yes/yes } \\
\text { No/no }\end{array}$ & $\begin{array}{l}99464 / 99463 \\
85832 / 87187\end{array}$ & $\begin{array}{r}-1.79 /-1.82 \\
+0.61 /+0.26\end{array}$ & $\begin{array}{r}\text { Yes/yes } \\
\text { Yes/no }\end{array}$ & $\begin{array}{l}71526 / 71525 \\
62539 / 63473\end{array}$ \\
\hline Central-eastern Europe (CEE) & $\left(44^{\circ} \mathrm{N}-50^{\circ} \mathrm{N}, 25^{\circ} \mathrm{E}-50^{\circ} \mathrm{E}\right)$ & $\begin{array}{r}-1.20 /-1.10 \\
+0.02 /+0.02\end{array}$ & $\begin{array}{r}\text { Yes/yes } \\
\text { No/no }\end{array}$ & $\begin{array}{l}45716 / 45699 \\
42347 / 42756\end{array}$ & $\begin{array}{r}-1.00 /-0.47 \\
+0.68 /+0.40\end{array}$ & $\begin{array}{l}\mathrm{No} / \text { no } \\
\mathrm{No} / \mathrm{no}\end{array}$ & $\begin{array}{l}31438 / 31405 \\
29310 / 29591\end{array}$ \\
\hline
\end{tabular}

and North-eastern Europe (NEE) which is situated on the northeast of CE. In all three cases, many grid cells with statistically significant weekly cycle are situated within each box region, especially in the case of MODIS TERRA. The other three regions selected are Central Mediterranean (CM), Eastern Mediterranean (EM) and Central-eastern Europe (CEE). They all present a moderately negative weekly cycle, with few grid cells with significant weekly cycle in the case of CM and CEE. Despite the fact that regions with a strong positive or negative weekly cycle are located within $\mathrm{QE}$, this region is characterized by a slightly negative WCI. This shows that QE should not be regarded as one region as far as weekly cycle is concerned. The exact geolocation of the 6 box regions examined here, including $\mathrm{QE}$, along with the corresponding average WCI values, the statistical significance and the observations used for the calculations, are given in Table 1.

As it was discussed in Sect. 2.2., the WCI could lead to false results for regions with low aerosol load due to the inclusion of small negative values in MODIS Collection 005 datasets. After applying the limit of $\pm 1000 \%$ to the $w_{\text {imy }}$ values used in the calculation of WCI the patterns were significantly "cleared" as seen in Fig. 1c and d. The corrected WCI values for the 6 regions are also cited in Table 1. Only $\sim 0.03 \%$ and $\sim 0.06 \%$ of the values is filtered during the correction for TERRA and AQUA which gives an indication of how few the anomalously high and low values are. The $\pm 1000 \%$ limit correction proves to be proper for the kind of analysis applied here since it combines effectiveness in clearing the patterns and preserving the statistical sample. The WCI data presented hereafter are from the new corrected dataset. Indicatively, two typical examples of false WCI values are presented in Fig. 2a, b for MODIS TERRA and AQUA, respectively. In the case of TERRA, the grid cell centered in $\left(37.5^{\circ} \mathrm{N}, 7.5^{\circ} \mathrm{W}\right)$ has two $w_{\text {imy }}$ values $(-1151 \%$ and $+10500 \%$ ) that exceed the limit of $\pm 1000 \%$ with all the other values ranging from $-312 \%$ to $+185 \%$ (Fig. 2a). This grid cell appears as an individual red pixel in the region of SWE which is generally covered by blue-green pixels (Fig. 1a). After subtracting those two anomalously high values, the WCI from highly positive $(+509 \%)$ turns to negative $(-5 \%)$, which is very close to the mean value for the region of SWE where the grid cell is located (Fig. 1c). The same situation stands for a neighbouring grid cell centered in $\left(38.5^{\circ} \mathrm{N}, 6.5^{\circ} \mathrm{W}\right)$ which appears as an individual orange pixel in SWE in the corresponding AQUA MODIS WCI map (Fig. 1b). After the subtraction of two positive values $(+1311 \%$ and $+2759 \%)$, which exceed the $\pm 1000 \%$ limit (Fig. 2b), the WCI turns from $+12.90 \%$ to $-1.23 \%$ (Fig. 1d). It has to be mentioned that the remaining $w_{\text {imy }}$ values range from $-777 \%$ to $+352 \%$ (Fig. $2 b$ ).

The impact on aerosol properties of Sahara dust episodic outbursts, which affect Europe and especially the regions around the Mediterranean Sea during spring and summer, has been thoroughly examined using satellite observations (e.g. MODIS, TOMS, SeaWiFS, etc.), ground-based observations (e.g. lidars, cimel sunphotometers, radiometers, PM ground stations, etc.) and models (e.g. DREAM, HYSPLIT, etc.) (Barnaba and Gobi, 2004; Papayannis et al., 2005; Tafuro et al., 2006; Kalivitis et al., 2007; Toledano et al., 2007; Meloni et al., 2007; Gkikas et al., 2009). In this work, two aerosol flags, presented in Sect. 2.2., have been applied only for diagnostic purposes on the already corrected data in order to eliminate the impact of episodic Sahara dust events. The differences between flag1 and flag2 corrected patterns are very limited (Supplement Fig. 1a, b, c, d). As expected, the general patterns did not change significantly 
a)

TERRA $\quad A D_{550} w_{\text {imy }}$ values for the grid centered in

lat: 37.500 and lon: -7.500

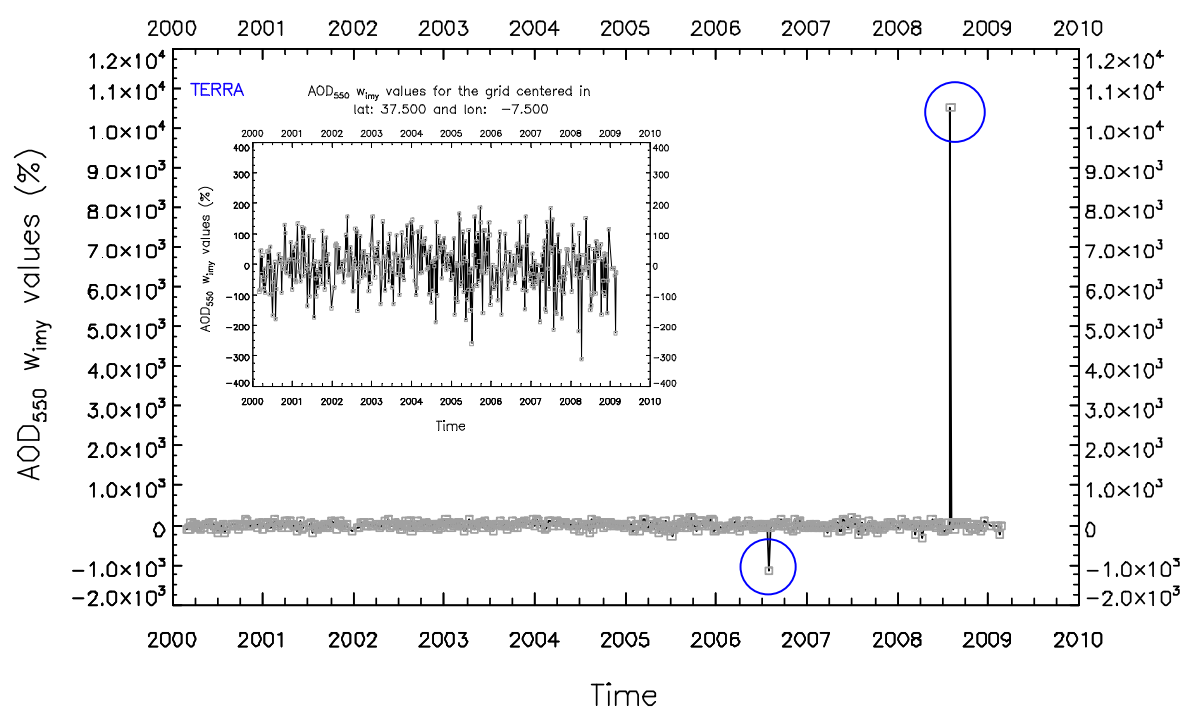

b)

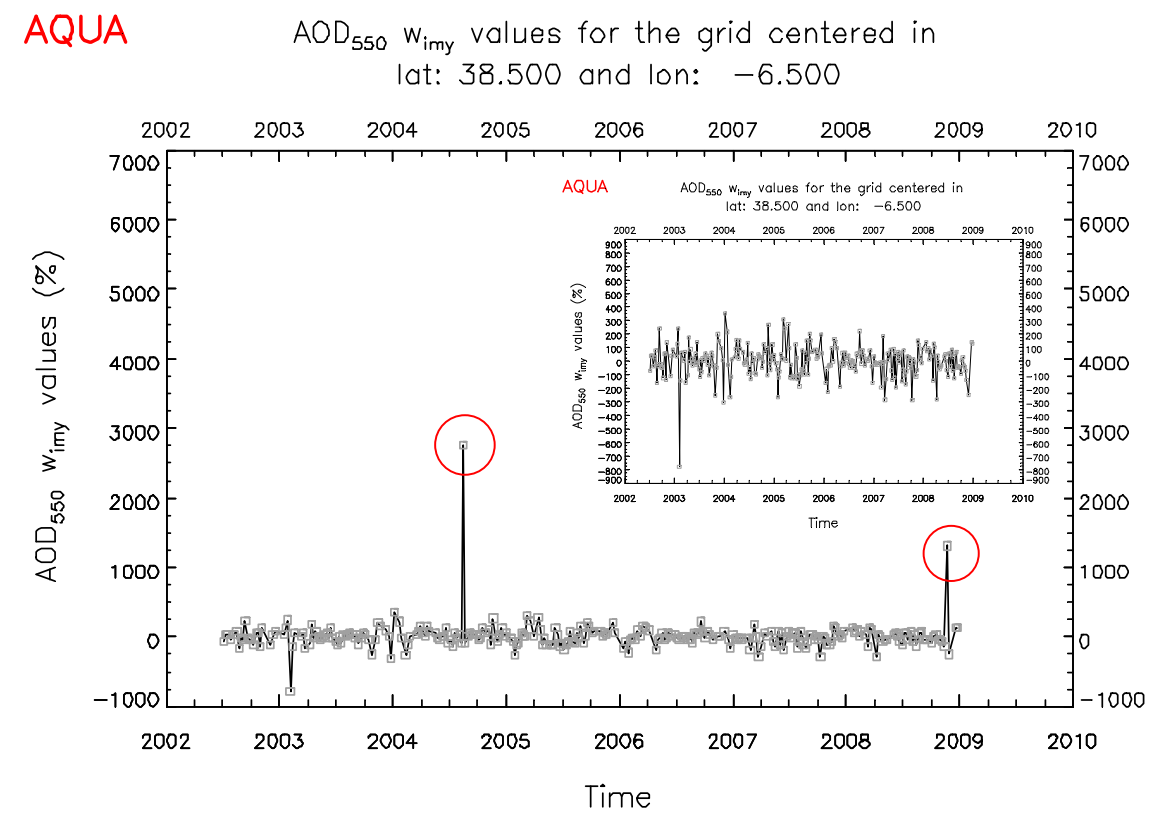

Fig. 2. $w_{\text {imy }}$ time series before (big panel) and after (small panel) the application of the $\pm 1000 \%$ limit correction for (a) TERRA MODIS $\mathrm{AOD}_{550}$ measurements for the grid cell centered in $\left(37.5^{\circ} \mathrm{N}, 7.5^{\circ} \mathrm{W}\right)$, (b) AQUA MODIS AOD 550 measurements for the grid cell centered in $\left(38.5^{\circ} \mathrm{N}, 6.5^{\circ} \mathrm{W}\right)$. In both figures the values that exceed the $\pm 1000 \%$ limit are encircled.

for continental regions in Europe which supports our decision to use only the $\pm 1000 \%$ limit corrected WCI values hereafter for the investigation of the spatial variability. Some small changes appear over the Mediterranean and the surrounding coastal regions. For CE and NEE there is practi- cally no change in the average WCI for both TERRA and AQUA. The average WCI remains negative but its absolute value decreases by $\sim 38 \%$ (TERRA) and $\sim 66 \%$ (AQUA) in the case of SWE due to an increase of WCI for the regions in southern and south-eastern Iberian Peninsula. This is more 
a)

TERRA

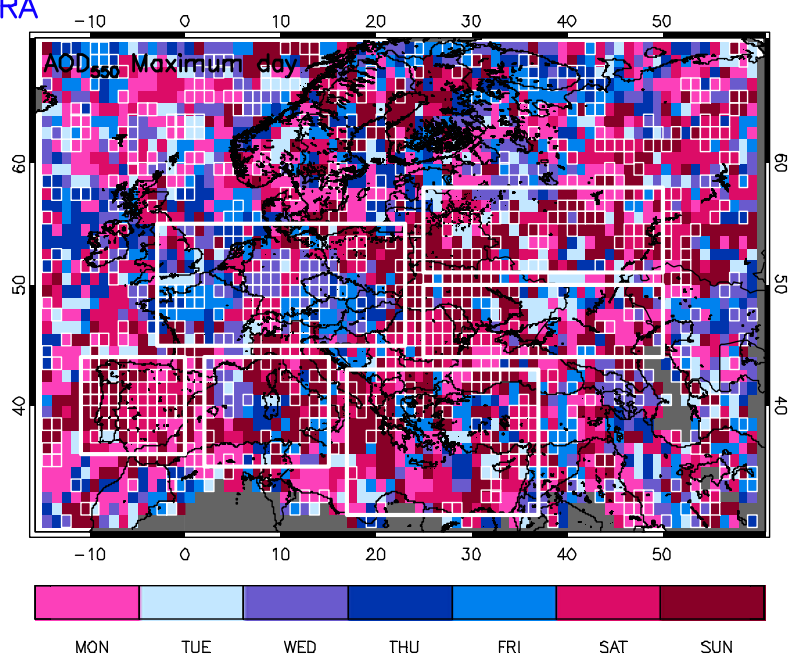

C)

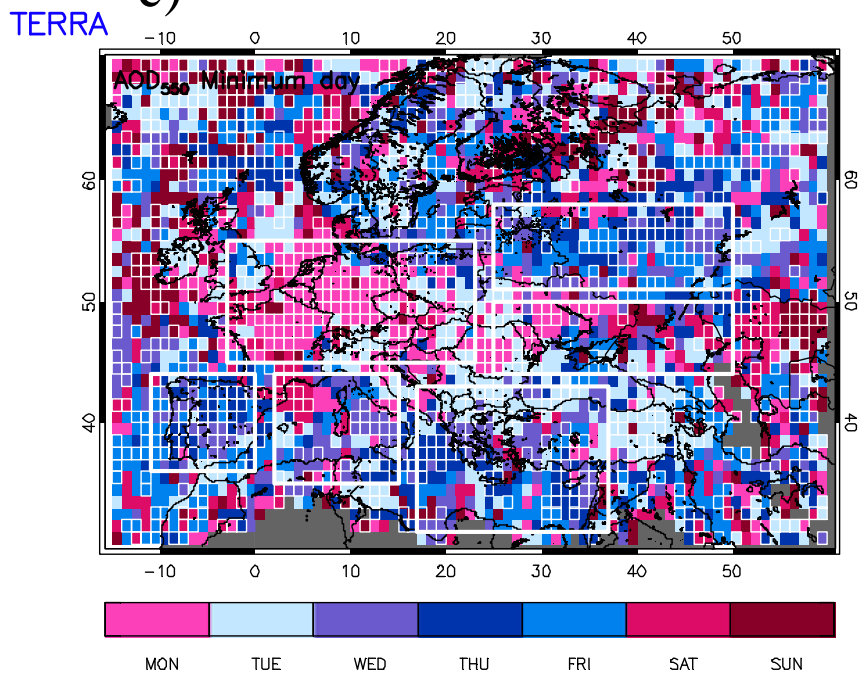

b)

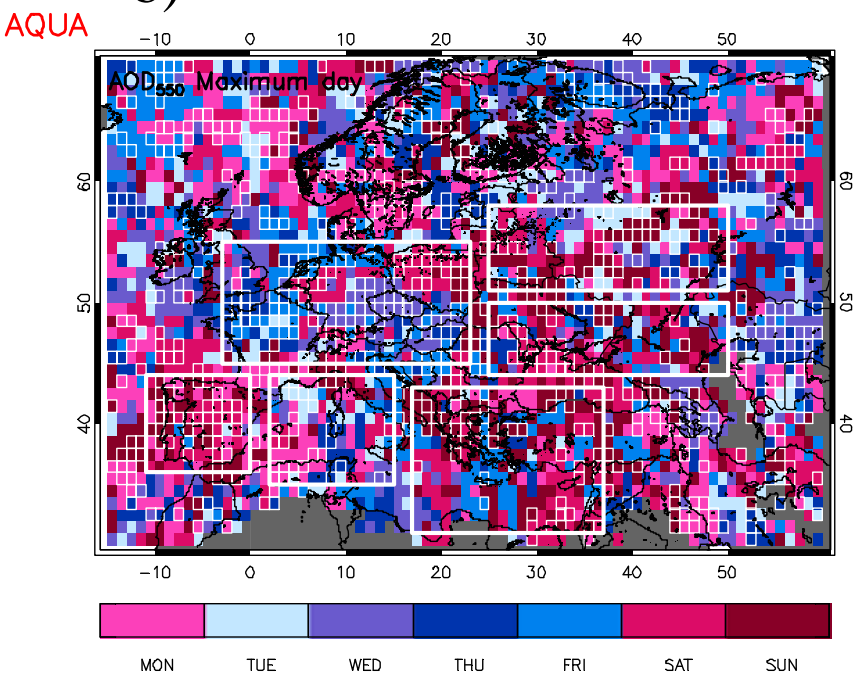

d)

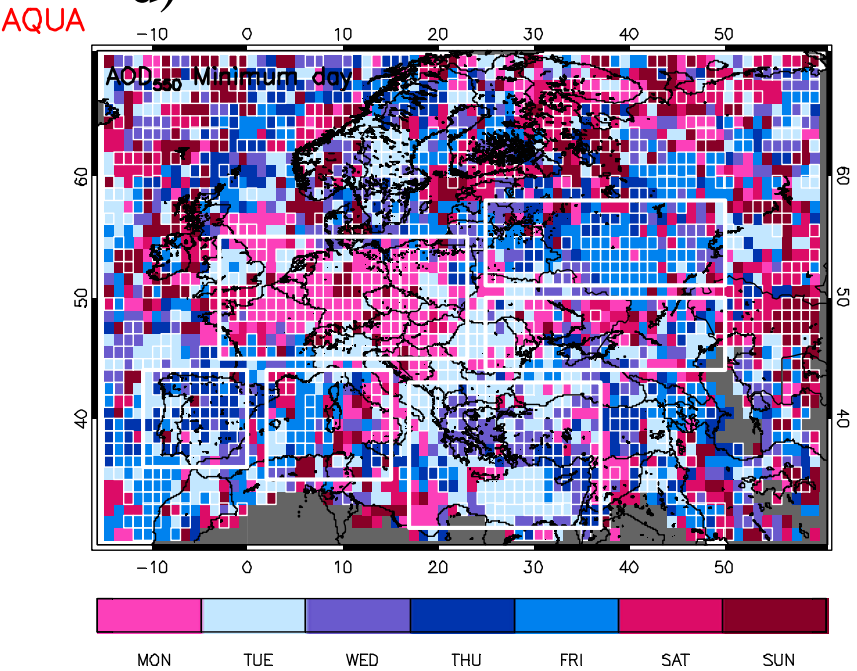

Fig. 3. (a, b) Day of maximum APD calculated from TERRA and AQUA MODIS AOD 550 measurements, (c, d) Day of minimum APD calculated from TERRA and AQUA MODIS AOD 550 measurements. The grid cells with a statistically significant value at the $90 \%$ confidence level according to the two tailed t-test appear with a thin white outline. The six regions of interest are marked with a thick white outline in all the maps.

obvious in the case of AQUA measurements. For CM the average WCI remains close to zero. The situation is quite similar for EM and CEE. Conclusively, the application of the two aerosol flags did not change significantly the weekly cycle patterns, indicating that the observed weekly cycles are due to continental aerosols.

\subsection{Day of maximum and minimum}

As discussed in Sect. 2.2., the APD of each day of the week from the weekly average was calculated from the $d_{i j m y \text {, new }}$ values for each grid cell separately. The days of maximum and minimum APD, for all the grid cells with available data, are presented in Fig. 3a, c for MODIS TERRA and Fig. 3b, $\mathrm{d}$ for MODIS AQUA. Grid cells with a statistically significant APD at the $90 \%$ confidence level according to the two tailed t-test appear with a thin white outline. The patterns in TERRA and AQUA case are quite similar. The patterns are not very smooth for the day of maximum APD. However, one can distinguish a midweek (Wednesday-ThursdayFriday) plume in the biggest part of CE with a small accumulation of weekend (Saturday-Sunday-Monday) grid cells on the north-eastern part of the region. SWE on the other hand presents a clear weekend maximum. NEE and CEE are mostly covered by weekend grid cells with only fewer neutral (Tuesday) and weekday grid cells. The same stands for CM 
Table 2. Day of maximum and minimum average percent departure from the weekly mean calculated from the spatial analysis (APD) and the corresponding APD values, day of maximum and minimum average percent departure from the weekly mean calculated from the region time series $\left(\mathrm{APD}_{\mathrm{ts}}\right)$ and the corresponding $\mathrm{APD}_{\mathrm{ts}}$ values, statistical significance at the $90 \%$ confidence level and the number of values included in the calculations, maximum and minimum APD calculated from the time series assuming hypothetical 6 and 8-day weeks, statistical significance of a 7-day cycle ( $90 \% / 95 \%$ confidence level) indicated from the spectral analysis applied on the time series.

\begin{tabular}{|c|c|c|c|c|c|c|c|c|}
\hline Region & $\begin{array}{l}\text { (TERRA) } \\
\mathrm{Max} / \mathrm{min} \text { day }(\mathrm{APD} \%) \\
\mathrm{Max} / \mathrm{min} \text { day }\left(\mathrm{APD}_{\mathrm{ts}} \%\right)\end{array}$ & $\begin{array}{r}\text { (TERRA) } \\
\text { Max-min APD diff. } \\
\text { Max-min APD } \text { ts }_{\text {diff. }}\end{array}$ & $\begin{array}{l}\text { (TERRA) } \\
\text { Signif. 90\% } \\
\text { Signif. } 90 \% \\
\text { 6/8d. signal } \\
\text { Sp. analysis }\end{array}$ & $\begin{array}{r}\text { (TERRA) } \\
\text { Values } \\
\text { Values }\end{array}$ & $\begin{array}{l}\text { (AQUA) } \\
\mathrm{Max} / \mathrm{min} \text { day }(\mathrm{APD} \%) \\
\mathrm{Max} / \mathrm{min} \text { day }\left(\mathrm{APD}_{\mathrm{ts}} \%\right)\end{array}$ & $\begin{array}{r}\text { (AQUA) } \\
\text { Max-min APD diff. } \\
\text { Max-min } \text { APD }_{\mathrm{ts}} \text { diff. }\end{array}$ & $\begin{array}{l}\text { (AQUA) } \\
\text { Signif. } 90 \% \\
\text { Signif. } 90 \% \\
\text { 6/8d. signal } \\
\text { Sp. analysis }\end{array}$ & $\begin{array}{r}\text { (AQUA) } \\
\text { Values } \\
\text { Values }\end{array}$ \\
\hline $\mathrm{CE}$ & $\begin{array}{l}\text { Wed }(+2.50) / \operatorname{Mon}(-5.54) \\
\text { Thu }(+2.08) / \operatorname{Mon}(-4.34)\end{array}$ & $\begin{array}{l}8.04 \\
6.42\end{array}$ & $\begin{array}{l}\text { Yes/yes } \\
\text { Yes/yes } \\
(2.52 / 2.15) \\
95 \%\end{array}$ & $\begin{array}{r}42995 / 41702 \\
458 / 452\end{array}$ & $\begin{array}{l}\text { Fri(+2.81)/Mon }(-6.30) \\
\text { Thu(+3.27)/Mon }(-4.30)\end{array}$ & $\begin{array}{l}9.11 \\
7.57\end{array}$ & $\begin{array}{l}\text { Yes/yes } \\
\text { Yes/yes } \\
(1.44 / 4.07) \\
95 \%\end{array}$ & $\begin{array}{r}29444 / 29245 \\
336 / 334\end{array}$ \\
\hline SWE & $\begin{array}{l}\operatorname{Sun}(+5.42) / \operatorname{Thu}(-3.89) \\
\operatorname{Sun}(+4.32) / \operatorname{Thu}(-4.07)\end{array}$ & $\begin{array}{l}9.31 \\
8.39\end{array}$ & $\begin{array}{l}\text { Yes/yes } \\
\text { Yes/yes } \\
(4.12 / 7.70) \\
95 \%\end{array}$ & $\begin{array}{r}26627 / 27112 \\
458 / 459\end{array}$ & $\begin{array}{l}\text { Sun }(+4.75) / \operatorname{Thu}(-5.89) \\
\text { Sun }(+4.32) / \operatorname{Thu}(-5.67)\end{array}$ & $\begin{array}{r}10.64 \\
9.99\end{array}$ & $\begin{array}{l}\text { Yes/yes } \\
\text { Yes/yes } \\
(4.71 / 6.60) \\
90 \%\end{array}$ & $\begin{array}{r}18959 / 19415 \\
335 / 337\end{array}$ \\
\hline NEE & $\begin{array}{l}\operatorname{Sun}(+8.05) / \text { Fri }(-4.85) \\
\operatorname{Sun}(+3.74) / \text { Fri }(-3.10)\end{array}$ & $\begin{array}{r}12.90 \\
6.84\end{array}$ & $\begin{array}{l}\text { Yes/yes } \\
\text { No/no } \\
(4.82 / 7.96) \\
-\end{array}$ & $\begin{array}{r}22527 / 24301 \\
320 / 324\end{array}$ & $\begin{array}{l}\text { Tue }(+3.68) / \text { Fri }(-6.53) \\
\text { Sun }(+5.00) / \text { Fri }(-4.94)\end{array}$ & $\begin{array}{r}10.21 \\
9.94\end{array}$ & $\begin{array}{l}\text { Yes/yes } \\
\text { Yes/yes } \\
(7.50 / 10.25) \\
-\end{array}$ & $\begin{array}{r}15151 / 16230 \\
219 / 226\end{array}$ \\
\hline $\mathrm{CM}$ & $\begin{array}{l}\operatorname{Sun}(+2.47) / \operatorname{Tue}(-1.33) \\
\operatorname{Sun}(+1.92) / \operatorname{Tue}(-1.35)\end{array}$ & $\begin{array}{l}3.80 \\
3.27\end{array}$ & $\begin{array}{l}\text { Yes/yes } \\
\text { No/no } \\
(1.49 / 6.48) \\
-\end{array}$ & $\begin{array}{r}37652 / 36950 \\
457 / 456\end{array}$ & $\begin{array}{l}\operatorname{Mon}(+1.37) / \operatorname{Fri}(-1.43) \\
\operatorname{Sat}(+1.07) / \operatorname{Fri}(-1.51)\end{array}$ & $\begin{array}{l}2.80 \\
2.58\end{array}$ & $\begin{array}{l}\text { Yes/yes } \\
\text { No/no } \\
(2.14 / 7.73) \\
-\end{array}$ & $\begin{array}{r}26709 / 26859 \\
337 / 337\end{array}$ \\
\hline EM & $\begin{array}{l}\operatorname{Sun}(+2.03) / \operatorname{Wed}(-1.57) \\
\operatorname{Sun}(+2.50) / \operatorname{Wed}(-1.89)\end{array}$ & $\begin{array}{l}3.60 \\
4.39\end{array}$ & $\begin{array}{l}\text { Yes/yes } \\
\text { Yes/yes } \\
(2.10 / 7.09) \\
-\end{array}$ & $\begin{array}{r}76527 / 77363 \\
458 / 459\end{array}$ & $\begin{array}{l}\text { Sun }(+3.04) / \text { Tue }(-2.76) \\
\operatorname{Sun}(+2.58) / \text { Tue }(-2.89)\end{array}$ & $\begin{array}{l}5.80 \\
5.47\end{array}$ & $\begin{array}{l}\text { Yes/yes } \\
\text { No/yes } \\
(2.25 / 6.60) \\
-\end{array}$ & $\begin{array}{r}54229 / 52819 \\
335 / 336\end{array}$ \\
\hline CEE & $\begin{array}{l}\operatorname{Sun}(+3.56) / \operatorname{Tue}(-1.38) \\
\operatorname{Sun}(+3.19) / \operatorname{Sat}(-2.55)\end{array}$ & $\begin{array}{l}4.94 \\
5.74\end{array}$ & $\begin{array}{l}\text { Yes/yes } \\
\text { Yes/yes } \\
(3.36 / 4.86) \\
-\end{array}$ & $\begin{array}{r}32517 / 31716 \\
451 / 454\end{array}$ & $\begin{array}{l}\text { Sun }(+4.17) / \operatorname{Tue}(-2.83) \\
\operatorname{Sun}(+1.43) / \operatorname{Thu}(-1.61)\end{array}$ & $\begin{array}{l}7.00 \\
3.04\end{array}$ & $\begin{array}{l}\text { Yes/yes } \\
\text { No/no } \\
(5.16 / 6.66) \\
-\end{array}$ & $\begin{array}{r}22148 / 21566 \\
334 / 335\end{array}$ \\
\hline
\end{tabular}

and EM but here the weekday grid cells are more and the patterns appear noisier. The day of minimum APD patterns are clearer. A Monday minimum plume is situated over CE extending partly into CEE. A midweek minimum appears over SWE and NEE. For CM and EM the majority of the grid cells present a neutral or midweek minimum. The existence of a neutral zone extending in the east of CE is indicative of an easterly moving weekly plume due to the prevailing synoptic conditions as discussed below.

Spatially averaged APDs were calculated using Eq. (3), and the weekly variability for each region, for both TERRA (blue) and AQUA MODIS (red), was examined (Fig. 4). In the case of CE a clear Monday minimum APD appears for both TERRA and AQUA datasets $(-5.54 \% /-6.30 \%)$. Saturdays and Sundays present a low positive or near zero APD. The variability between midweek days $(\sim 1 \%)$ is very small compared to the difference between the day of minimum and maximum in both cases $(8.04 \% / 9.11 \%)$. On the contrary, SWE exhibits a minimum APD on Thursday $(-3.89 \% /-5.89 \%)$ and a maximum on Sunday $(+5.42 \% /+4.75 \%)$. NEE exhibits a minimum APD on Friday $(-4.85 \%)$ and a maximum on Sunday $(+8.05 \%)$ for
TERRA MODIS. For AQUA, the day of minimum is Friday $(-6.53 \%)$ and the day of maximum is Tuesday $(+3.68 \%)$ with a second maximum of $+3.47 \%$ on Sunday. For CM, EM and CEE the weekly variability is generally negative but it is also much less stronger than it is for the previous three regions. Among the last three regions, CEE presents the strongest weekly variability with a minimum APD during Tuesday $(-1.38 \% /-2.83)$ and a maximum during Sunday $(+3.56 \% /+4.17 \%)$. The day of maximum and minimum APD along with the maximum and minimum APD values with the statistical significance at the $90 \%$ confidence level and their corresponding differences are cited in Table 2.

\subsection{A second approach for the investigation of weekly cycle}

As it was discussed in Sect. 3.1., the region selected by Quaas et al. (2009) contains sub-regions with differing weekly cycles. It is shown here that the method could be better applied only after a detailed spatial analysis where regions with common characteristics have been specified. The spectral analysis applied by Quaas et al. (2009) indicated 
a) CENTRALEUR

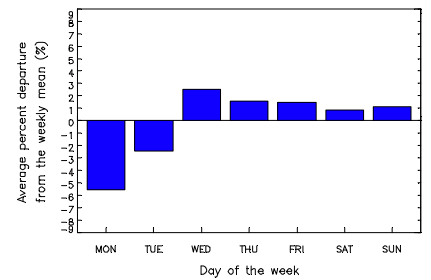

e)

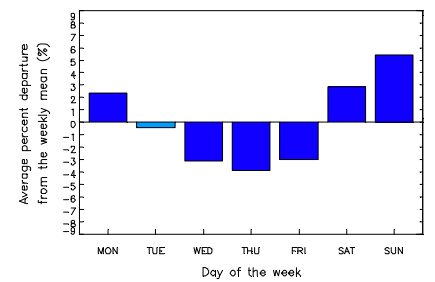

i)

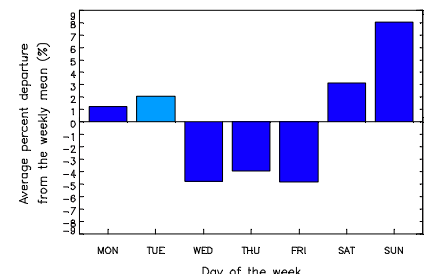

m)

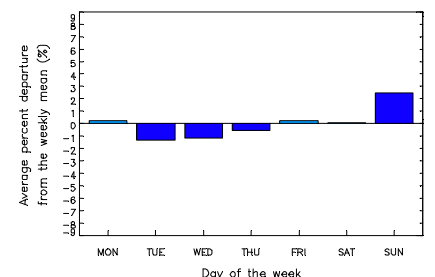

q)

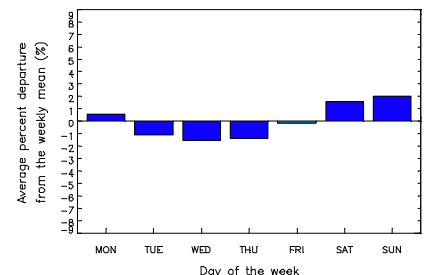

u)

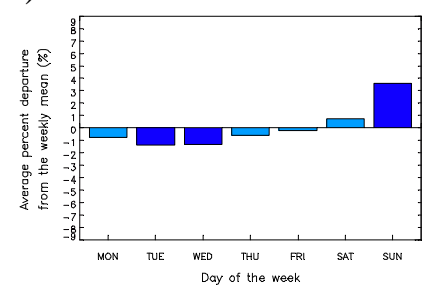

b) Central fur

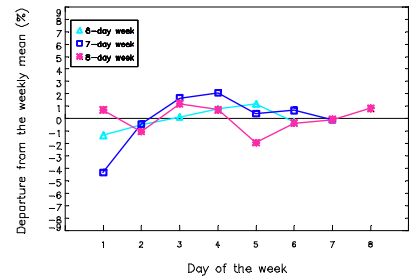

f) SOUTHWESTERN_EUR

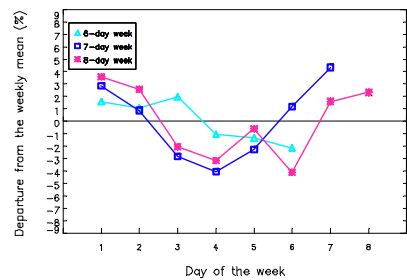

j) NORTHEASTERNEEUR

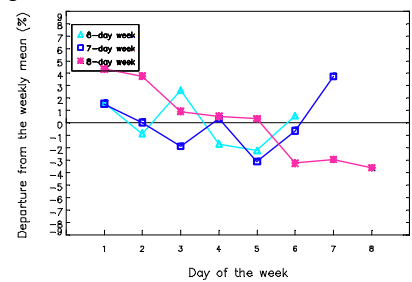

n) CENTRAL.MED

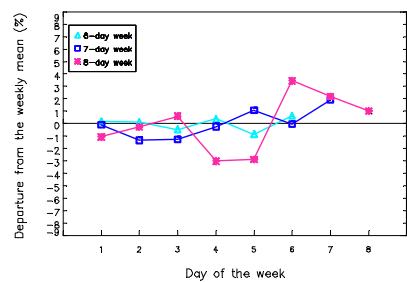

r) EASTERN_MED

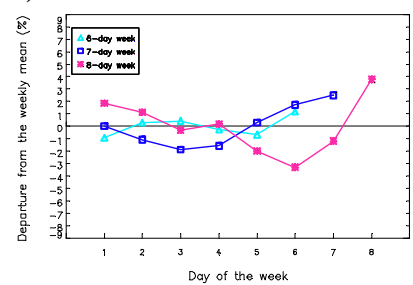

V) CENTRALEASTERN_EUR

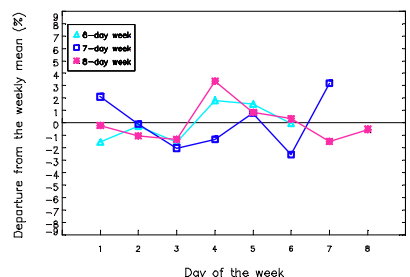

C) centraleur

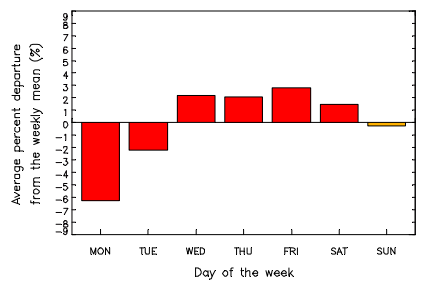

g) SOUTHWESTERN_EUR

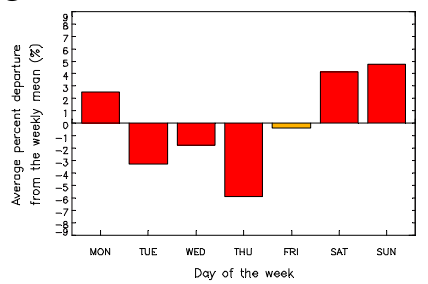

k) NORTHEASTERN_EUR

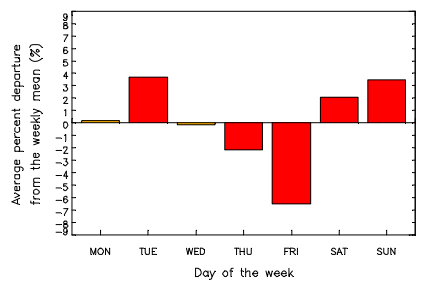

o)

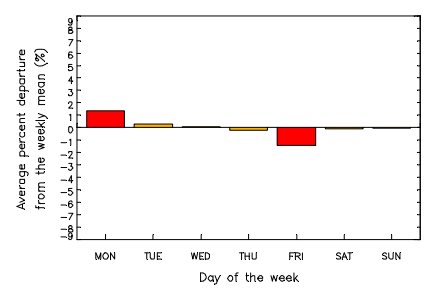

S) EASTERn_med

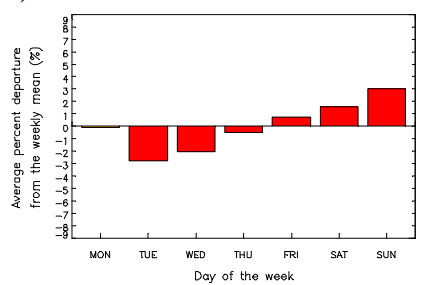

W) CEnTRALEASTERn_Eur

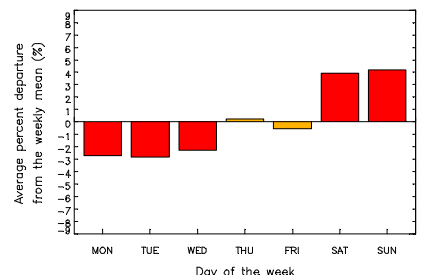

d) central fur

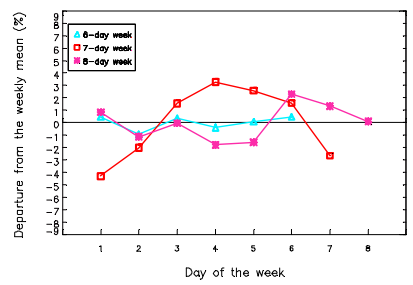

h) SOUTHWESTERN_EUR

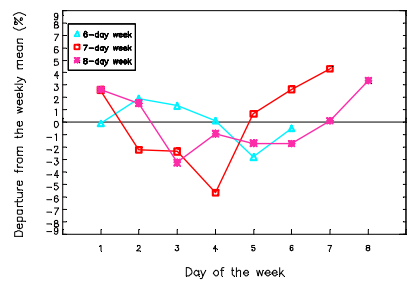

1) NORTHEASTERn_EUR

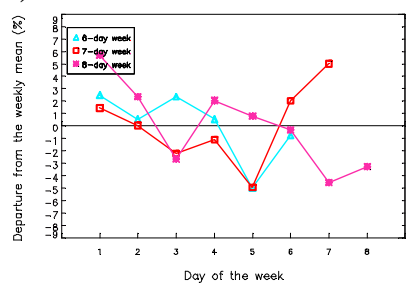

P) centralmmed

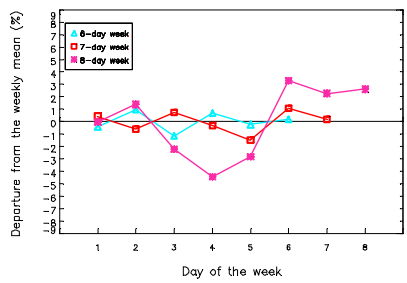

t) EASTERN_MED

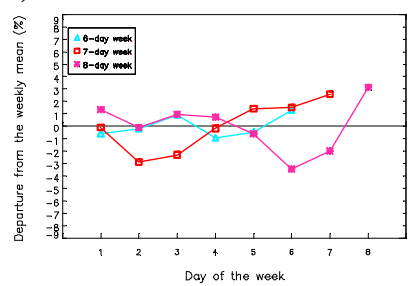

X) Centraleastern_eur

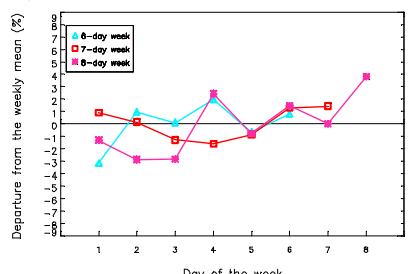

Fig. 4. Weekly variability of (a) spatially averaged APDs calculated using TERRA MODIS (blue bars) AOD 550 grid measurements for the period February 2000-February 2009 for CE (APDs that are not statistically different than zero at the $90 \%$ confidence level according to a two-tailed t-test are indicated with a light blue bar), (b) APDs calculated from the CE spatially averaged time series for 7 (blue), 6 (light blue) and 8-day (magenta) weeks (TERRA MODIS), (c) spatially averaged APDs calculated using AQUA MODIS (red bars) $\mathrm{AOD}_{550}$ grid measurements for the period July 2002-December 2008 for CE (APDs that are not statistically different than zero at the $90 \%$ confidence level according to a two-tailed t-test are indicated with a yellow bar), (d) APDs calculated from the CE spatially averaged time series for 7 (red), 6 (light blue) and 8-day (magenta) weeks (AQUA MODIS), (e, f, $\mathbf{g}, \mathbf{h})$ the same as (a, b, c, d) but for SWE, (i, j, $\mathbf{k}, \mathbf{l})$ the same as $(\mathbf{a}, \mathbf{b}, \mathbf{c}, \mathbf{d})$ but for NEE, (m, n, o, p) the same as (a, b, c, d) but for CM, (q, r, s, t) the same as (a, b, $\mathbf{c}, \mathbf{d})$ but for EM, $(\mathbf{u}, \mathbf{v}, \mathbf{w}, \mathbf{x})$ the same as $(\mathbf{a}, \mathbf{b}, \mathbf{c}, \mathbf{d})$ but for CEE. 
no statistical significance for the 7-day cycle of MODIS TERRA and AQUA AOD 550 time series. However, as shown below, for smaller regions in Europe with a strong and uniform weekly cycle the spectral analysis indicates a statistically significant $\mathrm{AOD}_{550}$ 7-day cycle.

Daily area averages have been calculated for each one of the 6 box regions. 12 time series ( 6 for TERRA and 6 for AQUA) were then analyzed separately. The APD for the 7 , 6 and 8-day weeks appears in Fig. 4. Each subfigure has been put next to the corresponding figure that emerged from the spatial analysis, for easier comparison of the two methods. The day of maximum and minimum percentage deviation along with the deviation values, their statistical significance at the $90 \%$ confidence level, the difference between maximum and minimum APD and the corresponding difference for the 6 and 8-day weeks are cited in Table 2 together with the corresponding results from the spatial analysis. The APDs emerging from the method presented in this paragraph are in general in good agreement with the results from the spatial analysis. Each method has its own advantages and disadvantages. Indicatively we could say that the spatial analysis captures the relative contribution of each grid cell to the APD in a better way. On the other hand, the second approach could eliminate the contribution of episodically high values which could insert drawbacks because the data are spatially averaged before the calculation of the APD. A great advantage of the second approach is that it allows for a further investigation of the statistical significance through the spectral analysis technique (Sect. 2.2.) which was applied on the time series. Whether the 7-day period is statistically significant at the $90 \%$ or $95 \%$ confidence level or not is indicated in Table 2.

For CE, a clear midweek peak with a Monday APD minimum appears for both TERRA and AQUA datasets $(-4.34 \% /-4.30 \%)$. Saturdays and Sundays present a low positive or near zero APD for TERRA MODIS. AQUA MODIS Sundays, in contrast to the spatial analysis, present a highly negative APD. Thursday is the day of maximum APD $(+2.08 /+3.27 \%)$ in both datasets. The difference between the day of minimum and maximum is higher in the case of AQUA $(7.57 \%)$ than TERRA $(6.42 \%)$ which is in agreement with the spatial analysis. All the minima and maxima are statistically significant at the $90 \%$ confidence level. The statistical significance is supported by the fact that for both TERRA and AQUA the 7-day signal is much stronger than the 6 and 8-day signal as shown in Fig. $4 \mathrm{~b}$ and d. The spectral analysis has shown that the 7-day cycle is statistically significant at the $95 \%$ confidence level for both datasets. In agreement to the weekly variability from the spatial analysis, SWE presents a clear weekend peak with minimum APD on Thursday $(-4.07 \% /-5.67 \%)$ and a maximum on Sunday $(+4.32 \% /+4.32 \%)$. The minima and maxima are statistically significant at the $90 \%$ confidence level. The 6 and 8-day hypothetical week maximum/minimum APD difference, as shown in Table 2, is lower than in the 7-day case which could be indicative of the significance of the 7-day cycle. The spectral analysis has revealed that the 7-day cycle is statistically significant at the $95 \%$ confidence level for the MODIS TERRA dataset and at the $90 \%$ for the MODIS AQUA dataset. Like SWE, NEE exhibits a clear weekend peak and weekday minimum. The minimum APD appears on Friday $(-3.10 \% /-4.94 \%)$ while the maximum APD appears on Sunday $(+3.74 \% /+5.00 \%)$ being statistically significant at the $90 \%$ confidence level only for AQUA MODIS. This is possibly attributed to the inclusion in the calculations of very few but also very noisy winter measurements in the case of TERRA MODIS only, which undermine the statistical significance (see Sect. 3.4.1). The 6-day week signal is lower than the 7-day signal. On the contrary, the 8-day signal is stronger or comparable to the 7-day signal which could be indicative of the synoptic transport of aerosols which extends the 7-day cycle by one day. We decided not to apply a spectral analysis on the NEE time series, given the very large percentage of missing winter values (whole months of data missing) over that region. In agreement to the spatial analysis results, the weekly variability for CM is not clear with the weekly variability being low for both TERRA and AQUA datasets. A statistical significance is not supported either from the two-tailed t-test or from the comparison with the 6 and 8-day signal and from the spectral analysis. EM on the other hand exhibits a low but clear negative (weekdays lower than weekdays) weekly cycle. In agreement to the spatial analysis, a maximum APD appears on Sunday $(+2.50 \% /+2.58 \%)$ for both datasets while a minimum APD appears on Wednesday $(-1.89 \%)$ and Tuesday $(-2.89 \%)$ for TERRA and AQUA correspondingly. The 8-day signal is stronger comparable to the 7-day signal which could be indicative of the synoptic transport of aerosols, extending the 7-day cycle by one day. The spectral analysis showed that the 7-day cycle is not statistically significant at the $90 \%$ or 95\% confidence level for both TERRA and AQUA. Unlike the other regions, the weekly variability over CEE, with relatively high positive APD values on Mondays, differs significantly from the variability inferred from the spatial analysis despite the fact that the general idea of midweek minimum and weekend maximum is preserved. Moreover, the variability is rather different for the TERRA and AQUA MODIS datasets (Fig. 4v, x). This, in addition to the fact that the 7 day signal is stronger than 6 and 8-day signal in the case of TERRA and weaker in the case of AQUA MODIS does not allow for clear conclusions about the weekly variability over this region. The 7-day cycle is not statistically significant according to the spectral analysis. It has to be mentioned here that the significance of a 6 and 8-day cycle was investigated through the spectral analysis for all the time series (excluding NEE) and in every single case statistical significance was not indicated.

The MODIS instruments are set to a near-polar sunsynchronous orbit and each successive pass occurs at roughly the same local sun time within a season. As discussed in 
Sect. 2.1., MODIS TERRA flies on a descending (southward) orbit with a daytime equator crossing time at 10:30 LT and MODIS AQUA flies on an ascending (northward) orbit with a daytime equator crossing time at 13:30 LT providing almost daily global coverage. An orbit is repeated every 16 days. As shown above, in this work we used data from the 2 sensors (each on a different satellite) separately for the investigation of the weekly cycle patterns and the weekly variability and the results were in very good agreement for the morning (TERRA) and noon (AQUA) measurements. Unlike other atmospheric parameters such as precipitation (see Bell et al., 2008) the AOD typically is not expected to vary substantially within a few hours. So, we conclude that any possible variability in the overpass time of each instrument due to its special orbital characteristics would not be able to introduce such large artifacts that would lead to a spurious weekly cycle. The 16-day repeat cycle could possibly insert 8-day periodicities; however, the spectral analysis shown above did not reveal a statistically significant 8-day (or 6day) periodicity in all cases. Our argument is further supported by analysis of level-2 $\left(10 \times 10 \mathrm{~km}^{2}\right.$ at nadir resolution $)$ MODIS TERRA data, where we have found correlations in WCI variability and population density (results not shown here), which would not be expected if the observed WCI was an artifact resulting from orbital periodicities. In addition, we have found a good agreement between independent MODIS and ISCCP (International Satellite Cloud Climatology Project) cloud cover weekly cycle patterns (unpublished results), which would not be the case if the weekly cycle was an artifact introduced by the special orbital characteristics of MODIS.

\subsection{Seasonal variability}

Apart from the identification of the general weekly cycle patterns and the investigation of the weekly variability of AOD $_{550}$ over Europe the same quantities should also be examined on a seasonal basis. In this way, one can discriminate whether the weekly patterns are stable throughout the year and connect spatial and temporal variations with the dominating synoptic conditions in the greater area. The seasonal WCI patterns for MODIS TERRA and AQUA appear in Fig. 5. The average seasonal WCI values for the 6 box regions along with the seasonal $\mathrm{AOD}_{550}$ and $\mathrm{FMR}_{550}$ levels are cited in Table 3 . The $1^{\circ} \times 1^{\circ}$ MODIS AOD 550 dataset has been shown to give a good insight into the regional aerosol levels for Europe (Chubarova, 2009). A comparison of the seasonal WCI maps (Fig. 5) with the seasonal AOD 550 maps (not shown here), shows that strong positive/negative WCI patterns do not correlate with the high/low $\mathrm{AOD}_{550}$ patterns. Even for highly populated megacities (e.g. Moscow) the WCI does not reveal a strong weekly variability of $\mathrm{AOD}_{550}$ in contrast to what was observed from space for other pollution parameters like tropospheric $\mathrm{NO}_{2}$ (Beirle et al., 2003; Sitnov, 2010). Compared to the general WCI patterns, the sea- sonal WCI patterns appear noisier for DJF, MAM and SON. This should partially be expected since the seasonal averages are calculated from a fraction of the total WCI values and though more vulnerable to episodic events (e.g. dust outbreaks, forest fires, storms, etc.) which could lead to occasional high/low values or individual "bad" $\mathrm{AOD}_{550}$ retrievals which could lead to faulty WCI values. The WCI patterns are noisier for the northern and north-eastern parts of Europe which are the regions with typically fewer WCI values. On the contrary, the summer WCI patterns are very clear and strong, driving the general WCI patterns, as shown below. The APD for the 6 box regions, as calculated from the TERRA and AQUA time series, appears in Fig. 6. The day with maximum and minimum APD and the corresponding APD values are cited in Table 3 .

In this work, we present an effort to correlate differing weekly cycle patterns appearing over Europe with the dominating seasonal wind patterns. The analysis presented in the following sections, suggests transport of aerosol weekly cycles from areas with strong weekly patterns to areas with small weekly variability of emissions. The average seasonal wind vectors at the $850 \mathrm{mbar}$ pressure level were calculated (Fig. 7a, c, e, g) together with the frequency distribution of the wind direction over the 6 box regions (Fig. $7 \mathrm{~b}, \mathrm{~d}, \mathrm{f}, \mathrm{h}$ ). The seasonal WCI patterns calculated after the application of aerosol flag1 and flag2 were used diagnostically as a tool for the identification of the continental character of the weekly cycle patterns appearing over specific regions (Supplement Fig. 2a-h). Only results from the application of aerosol flag1 are given in these figures, since the WCI patterns for flag1 and flag2 are almost identical. A detailed discussion for the seasonal weekly cycle patterns is presented below.

\subsubsection{Winter}

No conclusions can be reached for northern Europe during DJF, since MODIS aerosol retrievals are not feasible during winter for a large part of this area (see Fig. 5a, b), due to dominating cloud or snow/ice coverage (Remer et al., 2005). In addition, at low aerosol loading (optical thickness less than 0.15 ) which is the case for winter in this area, because of less signal, there is greater susceptibility to all algorithmic and sensor uncertainties (Remer et al., 2005).

Although during winter the aerosol patterns over CE appear rather noisy, there still seem to be areas in the center of this region with a strong positive cycle. The average WCI for DJF is $+2.82 \%$ for TERRA and $+3.35 \%$ for AQUA. There is a positive WCI plume extending over CEE $(+7.31 \% /+15.09 \%)$ and parts of EM $(+0.83 \% /+2.99 \%)$ (Fig. $4 a, b$ ). The fact that the highly positive and statistically significant grid cells are situated strictly over land areas over the whole Balkan Peninsula and the region of CEE above the Black Sea could be indicative of a local origin of this weekly plume. The wind speeds over this region are relatively low (Fig. 7a), creating favourable conditions for 
a)

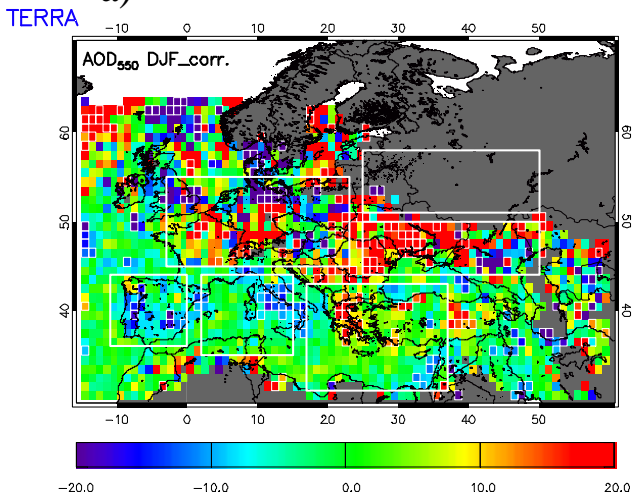

C)

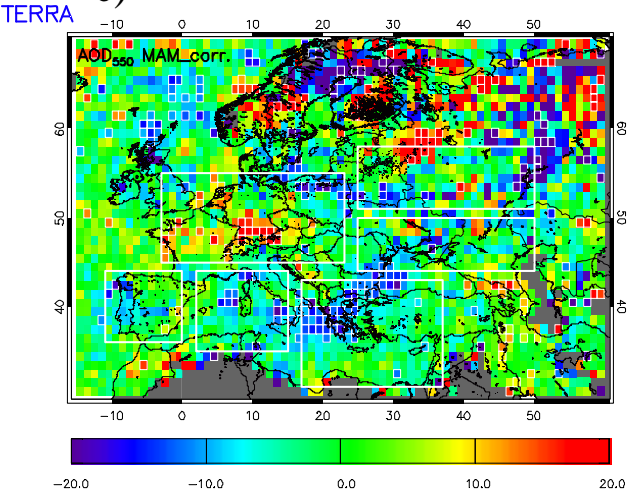

e)

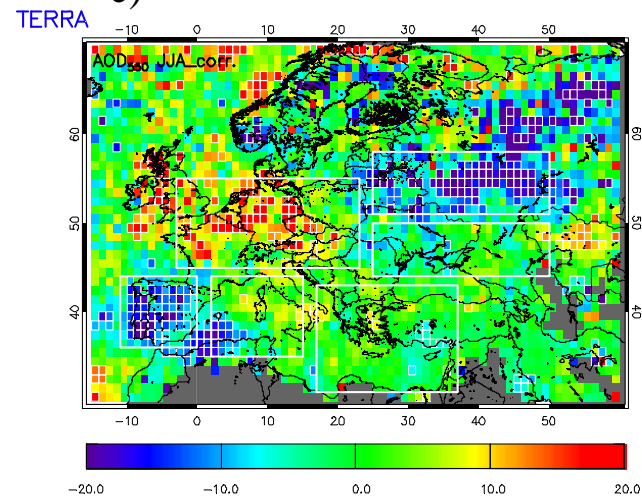

g)

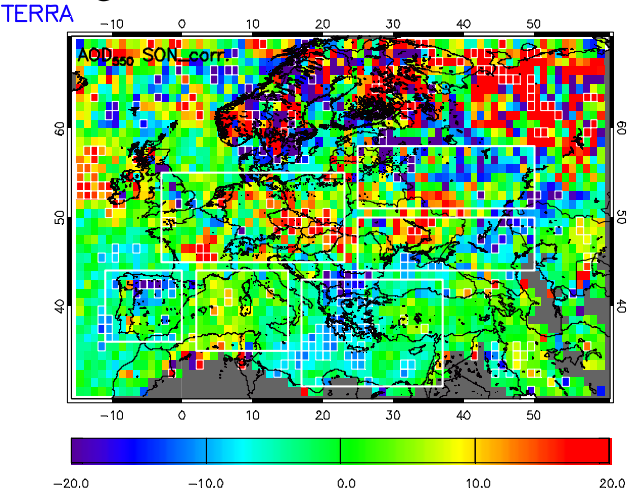

b)

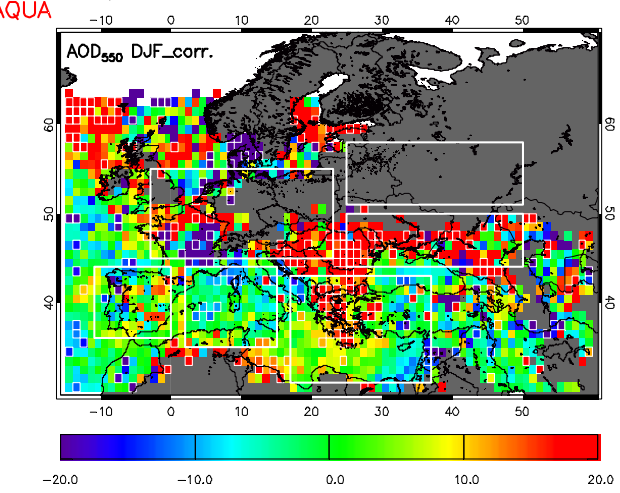

d)

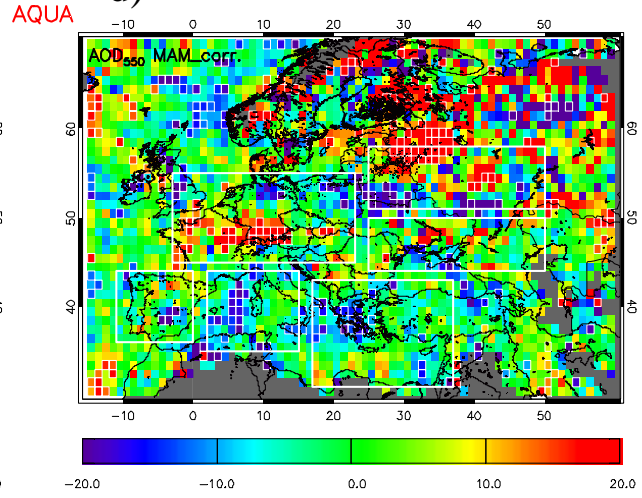

f)

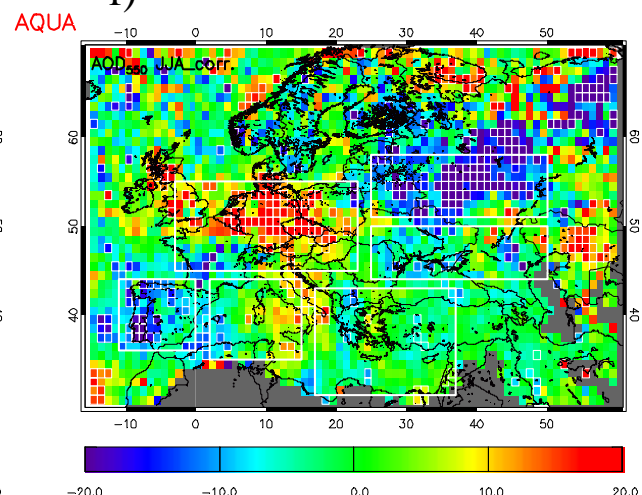

h)

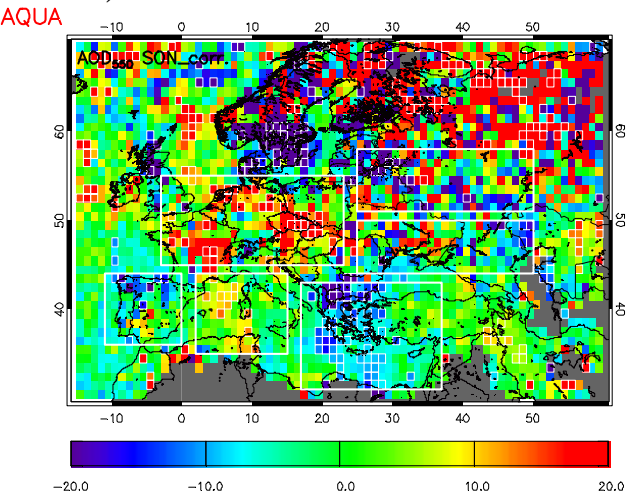

Fig. 5. Seasonal WCI patterns calculated from MODIS AOD 550 measurements corrected with the $\pm 1000 \%$ limit (a) DJF TERRA (February 2000-February 2009), (b) DJF AQUA (July 2002-December 2008), (c) the same as (a) but for MAM, (d) the same as (b) but for MAM, (e) the same as (a) but for JJA, (f) the same as (b) but for JJA, (g) the same as (a) but for SON, (h) the same as (b) but for SON. The grid cells with a statistically significant value at the $90 \%$ confidence level according to the two tailed t-test appear with a thin white outline. The 6 regions of interest are marked with a thick white outline in all the maps. 
a)

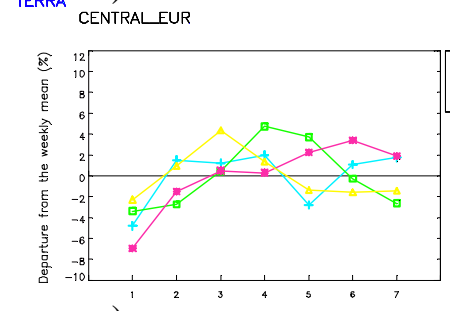

C)

SOUTHWESTERN_EUR

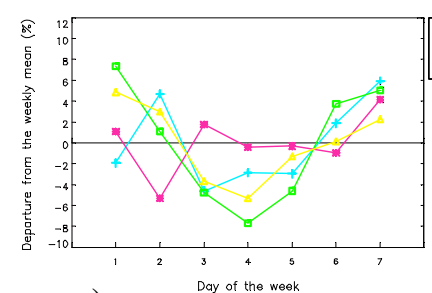

e)

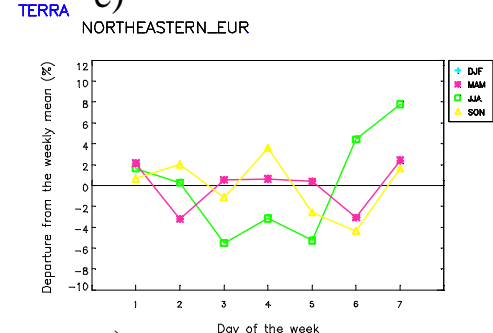

g)

CENTRALMED

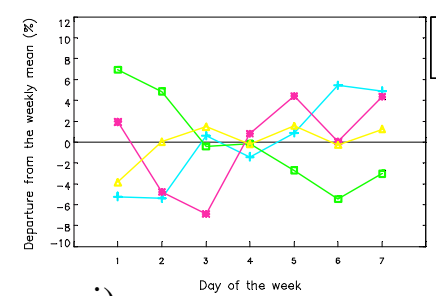

TERRA i) Day of the week

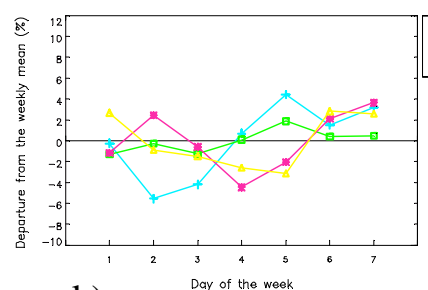

k)

CENTRALEASTERN_EUR

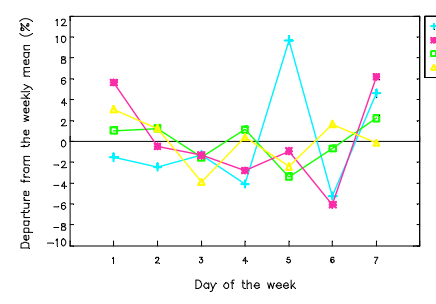

b)

CENTRALEUR

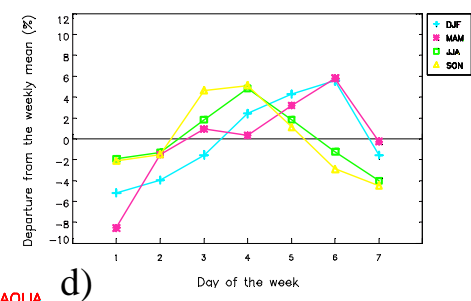

SOUTHWESTERN_EUR

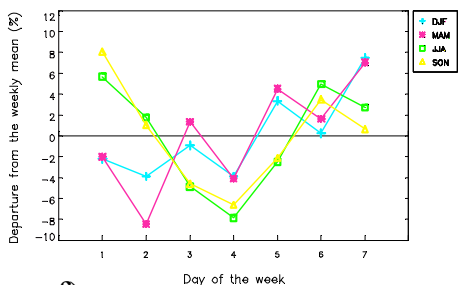

f)

NORTHEASTERN_EUR

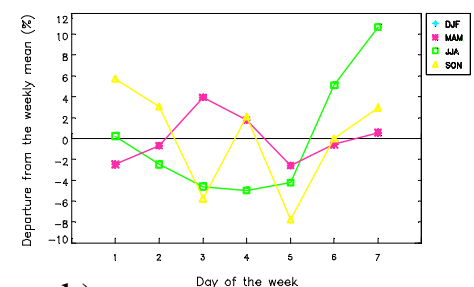

h)

CENTRALMED

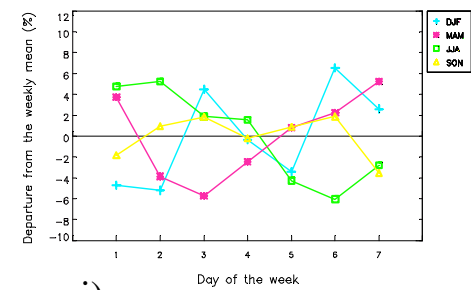

AQUA $\underset{\text { JEASTERN_MED }}{\text { j) }}$

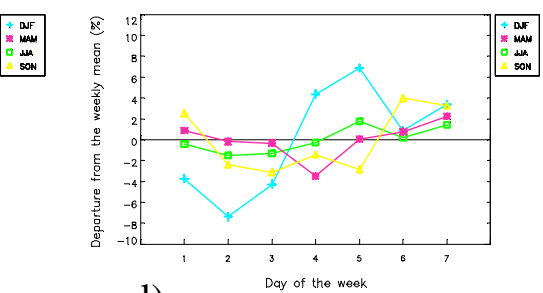

l)

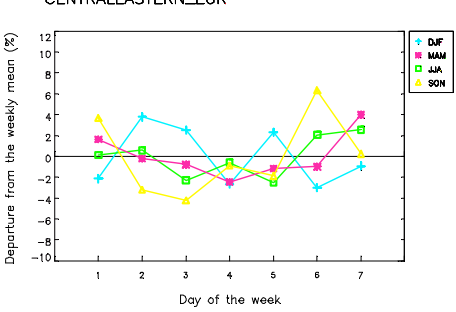

Fig. 6. Seasonal weekly variability of (a) APDs calculated from the CE spatially averaged time series for 7, 6 and 8-day weeks (TERRA MODIS: February 2000-February 2009), (b) APDs calculated from the CE spatially averaged time series for 7, 6 and 8-day weeks (AQUA MODIS: July 2002-December 2008), (c) the same as (a) but for SWE, (d) the same as (b) but for SWE, (e) the same as (a) but for NEE*, (f) the same as (b) but for NEE*, (g) the same as (a) but for CM, (h) the same as (b) but for CM, (i) the same as (a) but for EM, (j) the same as (b) but for EM, (k) the same as (a) but for CEE, (l) the same as (b) but for CEE. *Winter APD variability for NEE is not presented here due to the limited amount of $\mathrm{AOD}_{550}$ measurements. 
a)

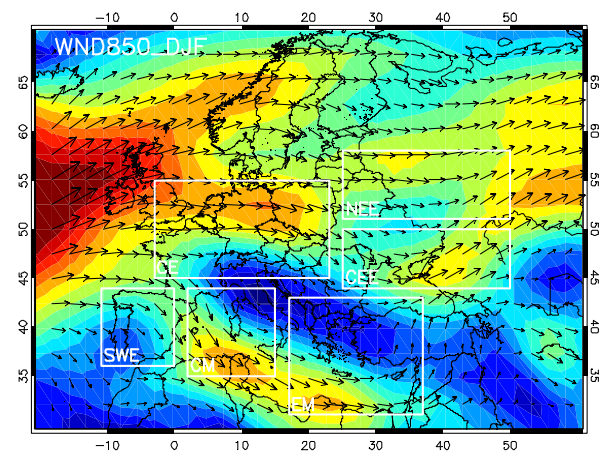

c)

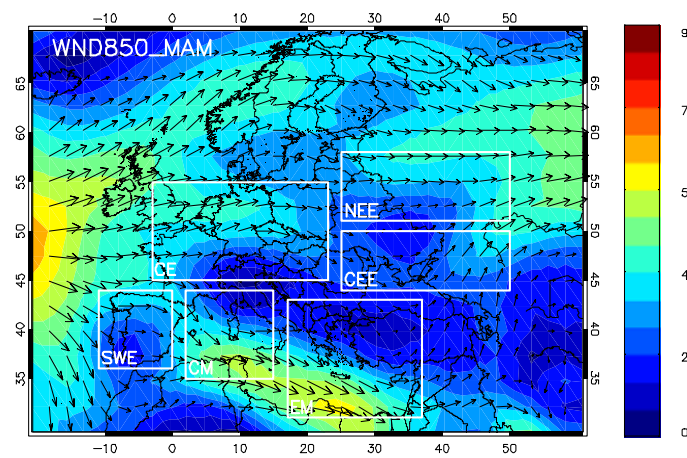

e)

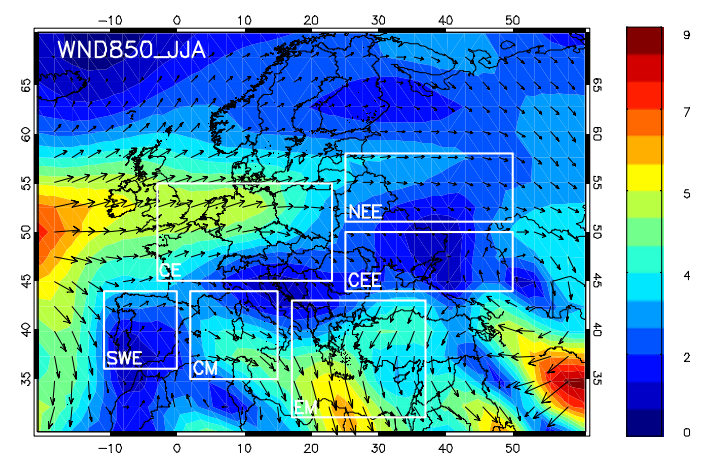

g)

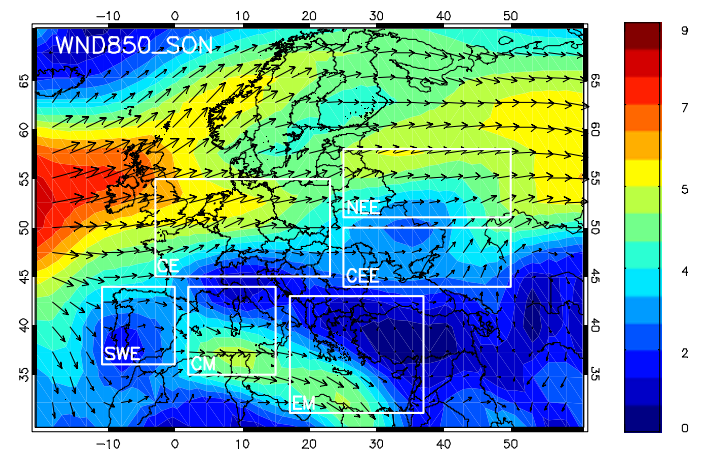

b)

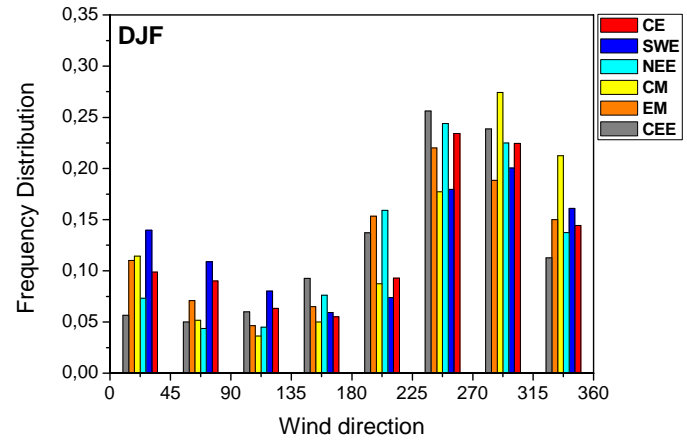

d)

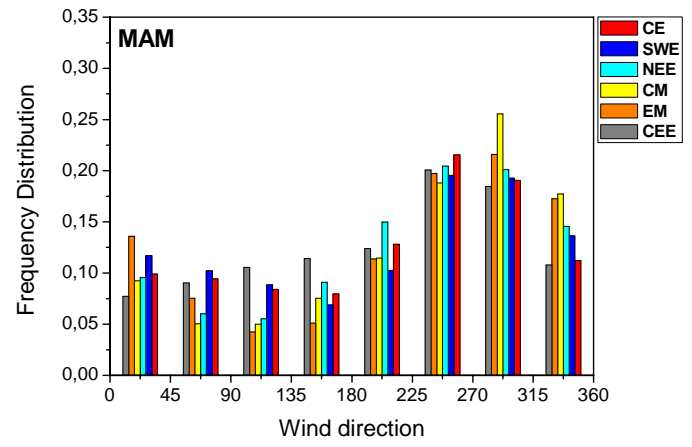

f)

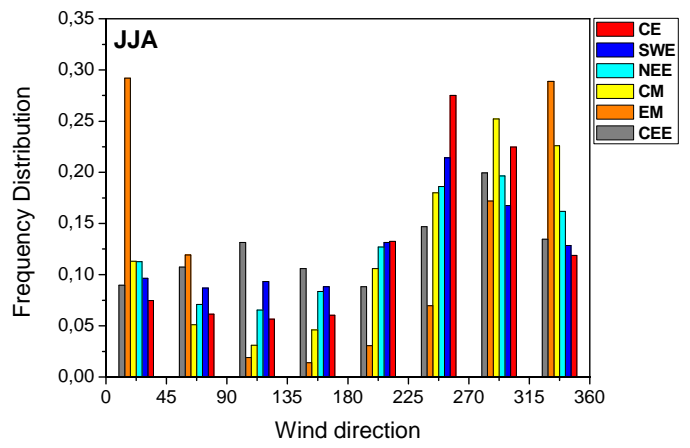

h)

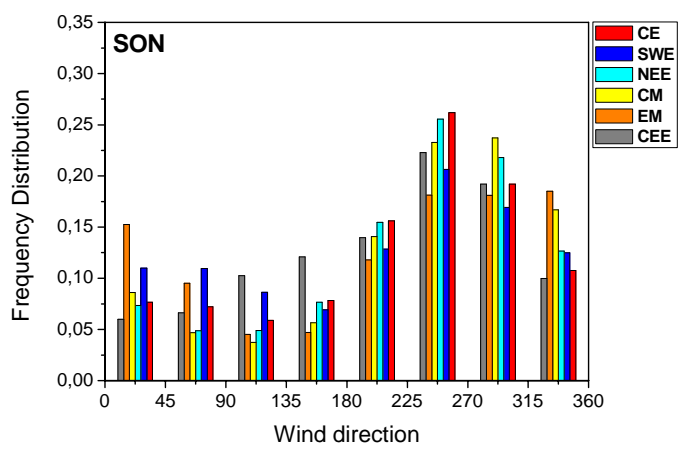

Fig. 7. (a) Average 2000-2009 NCEP/NCAR reanalysis wind speed (colorscale: 0-9 $\mathrm{m} \mathrm{s}^{-1}$ ) and vectors at the $850 \mathrm{mbar}$ pressure level for DJF, (b) Frequency distribution of the wind direction over the 6 regions of interest for DJF, (c) the same as (a) but for MAM, (d) the same as (b) but for MAM, (e) the same as (a) but for JJA, (f) the same as (b) but for JJA, (g) the same as (a) but for SON, (h) the same as (b) but for SON. 


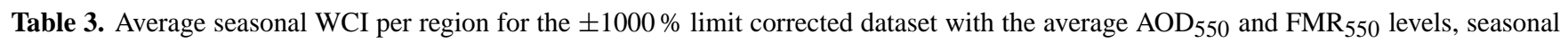
day of maximum and minimum average percent departure from the weekly mean calculated from the region time series $\left(\mathrm{APD}_{\mathrm{ts}}\right)$ and the corresponding $\mathrm{APD}_{\mathrm{ts}}$ values, statistical significance at the $90 \%$ confidence level and the number of values included in the calculations.

\begin{tabular}{|c|c|c|c|c|c|c|c|c|}
\hline $\begin{array}{l}\text { Region/ } \\
\text { Season }\end{array}$ & $\begin{array}{l}\text { (TERRA) } \\
\text { WCI }(\%)(\text { AOD/FMR) }\end{array}$ & $\begin{array}{l}\text { (TERRA) } \\
\text { Signif. } 90 \%\end{array}$ & $\begin{array}{l}\text { (TERRA) } \\
\text { Values }\end{array}$ & $\begin{array}{l}\text { (TERRA) } \\
\mathrm{Max} / \mathrm{min} \text { day }\left(\mathrm{APD}_{\mathrm{ts}} \%\right)\end{array}$ & $\begin{array}{l}\text { (AQUA) } \\
\text { WCI (\%) (AOD/FMR) }\end{array}$ & $\begin{array}{l}\text { (AQUA) } \\
\text { Signif. } 90 \%\end{array}$ & $\begin{array}{l}\text { (AQUA) } \\
\text { Values }\end{array}$ & $\begin{array}{l}\text { (AQUA) } \\
\mathrm{Max} / \mathrm{min} \text { day }\left(\mathrm{APD}_{\mathrm{ts}} \%\right)\end{array}$ \\
\hline $\mathrm{CE} / \mathrm{DJF}$ & $+2.82(0.15 / 0.40)$ & Yes & 6070 & Thu(+1.99)/Mon(-4.81) & $+3.35(0.13 / 0.47)$ & Yes & 2561 & $\operatorname{Sat}(+5.56) / \operatorname{Mon}(-5.18)$ \\
\hline CE/MAM & $+1.60(0.26 / 0.57)$ & Yes & 19539 & $\operatorname{Sat}(+3.40) / \operatorname{Mon}(-6.94)$ & $+2.71(0.25 / 0.62)$ & Yes & 12798 & $\operatorname{Sat}(+5.82) / \operatorname{Mon}(-8.54)$ \\
\hline CE/JJA & $+6.79(0.26 / 0.55)$ & Yes & 22345 & Thu(+4.73)/Mon(-3.38) & $+6.77(0.25 / 0.62)$ & Yes & 17249 & $\mathrm{Thu}(+4.82) / \operatorname{Sun}(-4.01)$ \\
\hline $\mathrm{CE} / \mathrm{SON}$ & $+4.02(0.16 / 0.52)$ & Yes & 17169 & $\operatorname{Wed}(+4.35) / \operatorname{Mon}(-2.30)$ & $+7.60(0.15 / 0.58)$ & Yes & 12003 & Thu(+5.13)/Sun(-4.48) \\
\hline SWE/DJF & $-4.69(0.11 / 0.39)$ & Yes & 8696 & $\operatorname{Sun}(+5.91) / \operatorname{Wed}(-4.62)$ & $+1.46(0.10 / 0.44)$ & No & 5731 & Sun(+7.48)/Tue $(-3.89)$ \\
\hline SWE/MAM & $-1.96(0.20 / 0.36)$ & Yes & 8516 & $\operatorname{Sun}(+4.14) / \operatorname{Tue}(-5.32)$ & $-1.41(0.19 / 0.39)$ & No & 5785 & $\operatorname{Sun}(+7.04) / \operatorname{Tue}(-8.46)$ \\
\hline SWE/JJA & $-11.03(0.21 / 0.31)$ & Yes & 9588 & $\operatorname{Mon}(+7.36) / \operatorname{Thu}(-7.71)$ & $-9.62(0.20 / 0.34)$ & Yes & 7356 & $\operatorname{Mon}(+5.67) / \operatorname{Thu}(-7.87)$ \\
\hline SWE/SON & $-4.63(0.15 / 0.37)$ & Yes & 9358 & $\operatorname{Mon}(+4.87) / \operatorname{Thu}(-5.32)$ & $-4.21(0.13 / 0.41)$ & Yes & 6930 & $\operatorname{Mon}(+8.07) / T h u(-6.60)$ \\
\hline NEE/DJF & $+1.84(0.16 / 0.14)$ & Yes & 43 & Tue(+11.59)/Fri(-19.91) & $-(0.16 / 0.26)$ & - & 0 & - \\
\hline NEE/MAM & $-2.71(0.22 / 0.65)$ & Yes & 10158 & $\operatorname{Sun}(+2.40) / \operatorname{Tue}(-3.22)$ & $+1.30(0.21 / 0.70)$ & No & 5920 & Wed(+3.96)/Fri(-2.59) \\
\hline NEE/JJA & $-12.16(0.19 / 0.74)$ & Yes & 15835 & $\operatorname{Sun}(+7.78) / \operatorname{Wed}(-5.54)$ & $-12.19(0.19 / 0.84)$ & Yes & 12329 & $\operatorname{Sun}(+10.69) / \operatorname{Thu}(-4.97)$ \\
\hline NEE/SON & $-2.48(0.16 / 0.52)$ & Yes & 8563 & Thu(+3.60)/Sat(-4.37) & $-3.73(0.16 / 0.61)$ & Yes & 5432 & $\operatorname{Mon}(+5.73) / F r i(-7.77)$ \\
\hline $\mathrm{CM} / \mathrm{DJF}$ & $-3.29(0.14 / 0.47)$ & Yes & 12451 & Sat(+5.43)/Tue(-5.39) & $-2.10(0.13 / 0.48)$ & Yes & 8377 & Sat $(+6.54) / \operatorname{Tue}(-5.21)$ \\
\hline CM/MAM & $-4.48(0.26 / 0.49)$ & Yes & 12243 & Fri $(+4.43) /$ Wed $(-6.89)$ & $-6.07(0.24 / 0.51)$ & Yes & 8292 & $\operatorname{Sun}(+5.26) / \operatorname{Wed}(5.73)$ \\
\hline $\mathrm{CM} / \mathrm{JJA}$ & $+0.02(0.27 / 46)$ & No & 12809 & $\operatorname{Mon}(+6.96) / \operatorname{Sat}(-5.46)$ & $+1.72(0.26 / 0.47)$ & Yes & 9710 & Tue $(+5.25) /$ Sat $(-6.05)$ \\
\hline $\mathrm{CM} / \mathrm{SON}$ & $+2.41(0.20 / 0.51)$ & Yes & 12883 & Fri $(+1.56) / \operatorname{Mon}(-3.84)$ & $+3.27(0.18 / 0.52)$ & Yes & 9811 & $\operatorname{Sat}(+1.88) / \operatorname{Sun}(-3.53)$ \\
\hline EM/DJF & $+0.83(0.18 / 0.49)$ & Yes & 22356 & Fri $(+4.44) /$ Tue $(-5.55)$ & $+2.99(0.18 / 0.50)$ & Yes & 15186 & Fri(+6.86)/Tue $(-7.39)$ \\
\hline EM/MAM & $-4.00(0.30 / 0.44)$ & Yes & 24714 & $\operatorname{Sun}(+3.65) / \operatorname{Thu}(-4.46)$ & $-2.96(0.29 / 0.46)$ & Yes & 16563 & $\operatorname{Sun}(+2.24) /$ Thu $(-3.48)$ \\
\hline EM/JJA & $+0.58(0.26 / 0.43)$ & Yes & 26194 & $\operatorname{Fri}(+1.88) / \operatorname{Mon}(-1.28)$ & $-0.67(0.25 / 0.44)$ & Yes & 19932 & Fri $(+1.75) /$ Tue $(-1.52)$ \\
\hline EM/SON & $-4.57(0.21 / 0.48)$ & Yes & 26198 & $\operatorname{Sat}(+2.82) / \mathrm{Fri}(-3.14)$ & $-5.70(0.20 / 0.49)$ & Yes & 19842 & Sat(+3.98)/Wed(-3.11) \\
\hline CEE/DJF & $+7.31(0.14 / 0.57)$ & Yes & 3992 & Fri $(+9.70) / \operatorname{Sat}(-5.26)$ & $+15.09(0.13 / 0.59)$ & Yes & 2217 & Tue $(+3.78) /$ Sat $(-3.01)$ \\
\hline CEE/MAM & $-2.47(0.21 / 0.69)$ & Yes & 13114 & $\operatorname{Sun}(+6.21) / \operatorname{Sat}(-6.07)$ & $+0.74(0.20 / 0.69)$ & No & 8151 & $\operatorname{Sun}(+3.98) /$ Thu $(-2.46)$ \\
\hline CEE/JJA & $-1.47(0.24 / 0.52)$ & Yes & 15826 & $\operatorname{Sun}(+2.21) / \operatorname{Fri}(-3.38)$ & $-3.25(0.23 / 0.58)$ & Yes & 11940 & $\operatorname{Sun}(+2.55) / \operatorname{Fri}(-2.49)$ \\
\hline CEE/SON & $-1.74(0.16 / 0.54)$ & Yes & 12760 & $\operatorname{Mon}(+3.09) / \operatorname{Wed}(-3.88)$ & $-2.22(0.15 / 0.54)$ & Yes & 9053 & Sat(+6.33)/Wed(-4.23) \\
\hline
\end{tabular}

the preservation of a local weekly cycle. For EM, the wind direction ranges from south-west (SW) to north-west (NW) $\left(225^{\circ}-315^{\circ}\right)$ with an average speed of $\sim 8.1 \mathrm{~m} \mathrm{~s}^{-1}$ for $\sim 41 \%$ and from NW to north-east (NE) $\left(315^{\circ}-45^{\circ}\right)$ directions with an average speed of $\sim 6.5 \mathrm{~m} \mathrm{~s}^{-1}$ for $\sim 26 \%$ of the days during winter. This could partly explain the existence of a positive cycle plume appearing over the central EM especially in the MODIS AQUA dataset. SW-NW air masses could transfer aerosols from the highly populated region of the Tunisian and Libyan coast in northern Africa where a strong positive weekly cycle is detected while NW-NE air masses could transfer particles from the Balkan Peninsula and CEE. Rough calculations, taking into account the distance that aerosols have to travel and the average wind speed per direction, show that in both cases air masses should travel about 1-2 days before reaching central EM. This could possibly lead to a positive WCI in the region. The continental origin of the positive plume appearing over the central EM, is supported from the fact that when we extracted the days where dust aerosols were dominating according to flag1 (which is the stricter criterion as discussed in Sect. 2.), the WCI pattern did not change (Supplement Fig. 2a, b). However, the application of the aerosol flag on the data erased the negative weekly plume appearing across the east coasts of Mediterranean. This suggests either that there are more dust particles during weekends over the region or that episodic events lead to this plume. Over SWE the WCI patterns are rather noisy and differ for MODIS TERRA $(-4.69 \%)$ and AQUA $(+1.46 \%)$ datasets. However, as mentioned above, the low aerosol loading over SWE (see Table 3) could insert significant uncertainties in the aerosol retrievals which would by extension propagate to the WCI calculations. Hence, DJF WCI values over SWE should not be considered reliable. Negative WCIs $(-3.29 \% /-2.10 \%)$ appear over CM. For $\mathrm{CM}$ the wind direction ranges from west (W) to north $(\mathrm{N})$ $\left(270^{\circ}-360^{\circ}\right)$ with an average speed of $\sim 8.8 \mathrm{~m} \mathrm{~s}^{-1}$ for almost half of the days. Air masses could be transferred from $\mathrm{CE}$ or SWE; however, a safe conclusion cannot be reached because, as mentioned above, the winter patterns are rather noisy for both CE and SWE. The weekly variability revealed through the APDs appearing in Fig. 6a-1 is quite different for MODIS TERRA and AQUA time series in many cases. The the variability is not very clear for CE, Monday being the day of minimum APD for MODIS TERRA. In the case of AQUA the weekly variability is clear, with a Friday-Saturday peak, Monday being the day of minimum again. The corresponding APD quantities for the total of the regions are cited in Table 3 . A clear weekly variability similar for TERRA MODIS and AQUA appears only in the case of EM. The variability is characterized by a Friday maximum and a Tuesday minimum for both datasets and is driven by the plume extending from the Balkans to the Libyan Sea.

\subsubsection{Spring}

During spring, a positive WCI plume appears in the center of CE with a strong negative cycle in the north-eastern part of this area (Fig. 5c, 5d). The strong positive plume 
covering regions situated in the region defined by the triangle of France-Germany-Switzerland is responsible for the positive mean WCI levels of CE $(+1.60 \% /+2.71 \%)$. Winds are much weaker than during DJF (see Fig. 7a, c) which favours the development of a local weekly cycle in a region with or near regions with a strong industrial activity and/or high population. The weekly patterns are rather noisy over SWE. The average WCI is $-1.96 \%$ and $-1.41 \%$ for MODIS TERRA and AQUA. The same stands for NEE and CEE with different results for MODIS TERRA and AQUA. The weekly cycle is negative for MODIS TERRA and positive for MODIS AQUA for both regions (see Table 3). The APD variability does not give a clear variability for NEE. On the other hand, CEE presents a clear variability for both datasets with weekday minima and weekend maxima (Fig.6, j) A negative weekly cycle plume is observed over CM giving average WCIs of $-4.48 \%$ (TERRA) and $-6.07 \%$ (AQUA). The average WCIs are also negative for EM for both the instruments $(-4.00 \% /-2.96 \%)$ with a strong negative plume covering the region defined by southern Italy, Adriatic Sea and southern Balkans. A weaker positive plume appears over the Libyan Sea primarily for the MODIS AQUA dataset. The negative plume appearing over CM and EM could be explained through the synoptic wind conditions which favour the transport of aerosols from CE (see Fig. 7c, d). During spring, the wind direction ranges from west $(\mathrm{W})$ to north-east $\left(270^{\circ}-45^{\circ}\right)$ with an average speed of $\sim 7.8 \mathrm{~m} \mathrm{~s}^{-1}$ for $\sim 40 \%$ of the days for CE. The corresponding wind speed and frequency values for $\mathrm{CM}$ are $\sim 7 \mathrm{~m} \mathrm{~s}^{-1}$ and $\sim 53 \%$. Following the same logic as in Sect. 3.4.1., the air masses arriving over $\mathrm{CM}$ from $\mathrm{CE}$ are expected to travel $\sim 1-2$ days on average. This shift is in good agreement with the weekly variability shown in Fig. 6a, b, g, and h, taking into account that a weekly variability of aerosols is not expected over CM. The day of maximum for CE is Saturday while the days with maximum APDs in CM are Sunday and Monday. For EM, the wind direction ranges from west to north $\left(270^{\circ}-360^{\circ}\right)$ directions with an average speed of $\sim 6.3 \mathrm{~m} \mathrm{~s}^{-1}$ for $\sim 40 \%$ of the days. The estimated average time for the transport of air masses from CE is $\sim 2-3$ days. This is in good agreement with the 3 days difference appearing in the day of minimum APD for EM and CE (Thursday/Monday). In order to verify this, we applied a lag-correlation on the CE and EM time series after deseasonalizing them by removing the monthly mean values. The correlation coefficient calculated assuming a lag of 3 days between the time series is higher than the coefficients calculated for other lags from 0 to 20 (figure not shown here). The continental character of the two negative WCI plumes is verified from the fact that the plumes are still visible on the maps (Supplement Fig. 2c, d) when applying the aerosol flags.

\subsubsection{Summer}

In contrast to the noisy patterns appearing in winter and spring, the summer WCI patterns are very clear. A comparison of the summer (Fig. 5e, f) and the general WCI patterns (Fig. 1c, d), shows that the summer weekly variability determines the annual weekly cycle. A very clear and distinct positive weekly cycle plume covers the whole CE extending over the British Islands to the north and over CM to the south. The WCI values are high $(+6.79 \% /+6.77 \%)$ and the strong weekly cycle is reflected to the clear and strong weekly variability shown in Fig. 6a and b. A Thursday maximum and a Sunday-Monday minimum with a max/min difference of $8-9 \%$ is observed for both MODIS TERRA and AQUA datasets. The extension of the Central-European plume to the south, perfectly matches the strong north-western mean flow at the 850 mbar pressure level appearing in Fig. 7e. Over $\mathrm{CE}$, wind direction ranges from south-west to north $\left(225^{\circ}-\right.$ $360^{\circ}$ ) for the $62 \%$ of the days with an average wind speed of $\sim 7.1 \mathrm{~m} \mathrm{~s}^{-1}$, bringing air masses from the CE to NEE, CEE, CM and EM (Fig. 7f). A strong negative WCI plume covers the whole NEE region extending to the northwest. The average WCI value is almost the same for TERRA and AQUA dataset $(-12.16 \% /-12.19 \%)$. The weekly variability shows a clear weekday minimum (Wednesday-ThursdayFriday) and a weekend maximum (Saturday-Sunday) with the max/min difference being in the order of $\sim 13-16 \%$ for the two instruments (Table 3). $\sim 2-3$ days is the expected time of the air mass transport from CE to NEE, which is supported from the results of the lag-correlation applied on the time series. The winds are relatively low over NEE, favouring the development of a weekly cycle. As it is apparent from the WCI levels over CEE, winds originating from CE could be responsible for the negative cycle appearing there. A Friday minimum and a Sunday maximum appears in both MODIS TERRA and AQUA datasets. During late summer the existence of a significant number of agricultural fires in the region around Ukraine is typical and could possibly impact the weekly variability. Like in the case of NEE, the weekly variability could be explained through the transport of air masses from the westerly dominating wind flow. The $\sim 2-3$ days difference between the CE and CEE maxima is also supported by a 2-3 days lag-correlation maximum of the time series (figure not shown here). A very interesting feature of Fig. 5e, $\mathrm{f}$ is the strong negative WCI plume $(-11.03 \% /-9.62 \%)$ covering the region around the Iberian Peninsula (also see Xia et al., 2008). This feature would not be expected to originate from $\mathrm{CE}$ since winds with northern to eastern direction dominate only for the $\sim 12-13 \%$ of the days in the region of CE and CM. Winds blowing from the opposite direction account for only $\sim 8 \%$ of the days, which rejects the assumption that aerosols could be transferred from the Algerian coast. Moreover, the maps with the WCI patterns after the application of the aerosol flags (Supplement Fig. 2e, f) reveal that the WCI patterns still remain 
negative. This shows that the negative weekly cycle is possibly of continental origin. The fact that the statistically significant highly negative grid cells are located over land and that winds are relatively mild over the region favours the assumption that this is a local weekly cycle. We could also not exclude the possibility that the cloud lifetime effect and by extension the storm invigoration effect could partly explain the negative weekly cycle appearing over SWE, especially in summer (see Bell et al., 2008). A direct response of clouds to the increase of aerosol emissions in the beginning of the week through the cloud lifetime effect would lead to increased cloud cover and suppressed precipitation. The storm invigoration effect could finally lead to an intense precipitation in midweek, washing out the aerosols (Rosenfeld et al., 2008). This scenario is supported by the fact that the negative weekly cycle is much stronger in summer when most clouds are of convective origin over the Iberian Peninsula. However, a more detailed work using aerosol, cloud and precipitation observations would allow for safer conclusions. The weekly variability over EM is very low during summer. The APD values appearing in Fig. 6i, $j$ are quite similar for TERRA and AQUA but the weekly variability is very weak. On the contrary the weekly variability over CM is strong with minimum APDs appearing on Saturday and Sunday and maximum APDs on Monday and Tuesday. CM seems to be influenced from air masses from both SWE and CE which lead to two separate plumes in the region. The north-eastern part is covered by a positive WCI plume while the south-western part from a strong negative WCI plume. Taking into account that over $\mathrm{CM}$ the wind direction ranges from west to north $\left(270^{\circ}-360^{\circ}\right)$ for $\sim 48 \%$ of the days with an average speed of $\sim 5.6 \mathrm{~m} \mathrm{~s}^{-1}$ during summer, the air masses originating from SWE and CE are supposed to arrive over CM within a day. The negative plume is probably the extension of the plume appearing over SWE and the positive an extension of the CE plume. The weekly variability shown in Fig. $6 \mathrm{~g}$, h is probably the result of the synoptic aerosol transport from SWE and CE with a maximum APD on Monday-Tuesday and a minimum on Saturday-Sunday.

\subsubsection{Autumn}

During autumn, the WCI patterns (Fig. 5g, h) share characteristics with the summer and spring WCI patterns. A significant positive WCI plume appears over CE $(+4.02 \% /+7.60 \%)$. The weekly variability is clear, being characterized by a midweek maximum (WednesdayThursday) and a weekend minimum (Saturday-SundayMonday) (Fig. 6a, b). The weekly patterns are negative over SWE with the average WCI being $-4.63 \%$ and -4.21 for MODIS TERRA and AQUA. The weekly variability here is very close to the summer variability (Fig. 6c, d), with a midweek minimum on Thursday and a weekend maximum on Monday with a max/min difference of $\sim 10 \%$ and $\sim 15 \%$ for TERRA and AQUA data correspondingly. As it is revealed from the WCI patterns and the weekly variability (Figs. $5 \mathrm{~g}$, $h, 6 e, f, k, l)$ the weekly cycle is not very clear over NEE and CEE. However, the average WCI values are negative for both the datasets which is in agreement to the summer values. The significant negative plume appearing over EM could be explained through the synoptic wind conditions which favour the transport of aerosols from CE (Fig. 7g, h). During autumn, the wind direction ranges from west to north $\left(270^{\circ}-360^{\circ}\right)$ for $\sim 30 \%$ of the days with an average speed of $\sim 9 \mathrm{~m} \mathrm{~s}^{-1}$ for CE (Fig. 7h). The corresponding values for EM are $\sim 37 \%$ and $\sim 5.6 \mathrm{~m} \mathrm{~s}^{-1}$. The result is a large significant negative weekly cycle appearing over the Balkan Peninsula and the Libyan Sea. This plume determines the weekly variability over EM. The lag-correlation between the CE and EM time series reveals a peak for a 3-4 days lag (figure not shown here). This is in good agreement with the reverse weekly variability appearing for EM and CE (Fig. 6a, b, i, j) and could explain the negative plume appearing over EM through the transport of continental aerosols from CE. A further indication of the continental origin of the plume is its persistence after the subtraction of the days where dust aerosols were the dominant type (Supplement Fig. 2, h). A strong positive WCI plume appears over CM. The patterns are similar for MODIS TERRA and AQUA with the average WCI levels being $+2.41 \%$ and $+3.27 \%$ respectively over CM. This plume is possibly an extension of the CE plume and its continental origin is verified by its persistence after the application of the aerosol flags (Supplement Fig. 2g, h).

\section{Summary and conclusions}

In the present study, a satellite-based index (WCI) expressing the mean percentage of the $\mathrm{AOD}_{550}$ difference between midweek and weekend to the weekly average was used for the spatial and temporal investigation of the regional patterns of aerosol weekly cycle over Europe. This method was originally used by Xia et al. (2008); however it is shown here that the method has limitations which should be taken into account when being applied. In order to remove episodic dust transport events, 2 different aerosol flags, employing FMR $_{550}$ and $\mathrm{AOD}_{550}$ data, were applied diagnostically. After the definition of the general weekly cycle patterns over Europe, 6 box regions with different weekly cycle characteristics were selected in order to generalize our results by spatially averaging. Daily area averages were then calculated for each one of the regions and a second method, originally proposed by Quaas et al. (2009), was applied on the time series. This method, in addition to the two-tailed t-test method, allows for a further investigation of the statistical significance through the comparison of the 7-day week signal with the signal of 6 and 8-day hypothetical weeks and a spectral analysis technique. In contrast to the results of Quaas et al. (2009), it is shown here that when this method is applied in smaller regions with a strong and uniform weekly 
cycle, statistical significance is indicated. The comparison of the weekly variability that emerged from the two aforementioned methods showed that the results are generally in good agreement.

The general WCI patterns from MODIS TERRA (February 2000-February 2009) and AQUA (July 2002December 2008) reveal 3 major weekly cycle plumes over Europe. Central Europe (CE) is characterised by a strong positive weekly plume with higher values during midweek than during weekend. Monday minima and Thursday maxima appear in both MODIS TERRA and AQUA AOD 550 datasets. The results are statistically significant according to the two-tailed test and the comparison with hypothetical 6 and 8-day week signal. In addition, the spectral analysis showed that the 7-day cycle is statistically significant at the $95 \%$ confidence level for both TERRA and AQUA. A strong negative weekly cycle plume appears over Southwestern Europe (SWE) (more distinct for MODIS TERRA data). A minimum average percent departure (APD) from the weekly mean appears on Thursday and a maximum on Sunday for both TERRA and AQUA. Statistical significance is indicated from the spectral analysis at the $95 \%$ and $90 \%$ confidence level for the MODIS TERRA and AQUA dataset correspondingly. A strong negative weekly cycle plume appears over North-eastern Europe (NEE) too. NEE exhibits a clear weekend peak and weekday minimum. The minimum APD appears on Friday and the maximum APD appears on Sunday, being statistically significant at the $90 \%$ confidence level only for AQUA MODIS, possibly due to the inclusion in the calculations of very few and noisy winter measurements in the case of TERRA MODIS. Statistical significance was not indicated here from the comparison of the 7-day week signal with the 6 and 8-day week signal, while a spectral analysis was not applied because of the very large percentage of missing winter values. The other 3 regions under investigation, Central Mediterranean (CM), Eastern Mediterranean (EM) and Central-eastern Europe (CEE), present a very low negative weekly cycle. Statistical significance is not indicated in the case of CM and CEE. EM exhibits a low but clear negative weekly cycle with a maximum APD appearing on Sunday for both TERRA and AQUA while a minimum APD appears on Wednesday and Tuesday for TERRA and AQUA respectively. Only the 8-day signal is stronger comparable to the 7-day signal which could be indicative of the synoptic transport of aerosols, extending the 7-day cycle by one day. The spectral analysis showed that the 7-day cycle is not statistically significant.

The investigation of the seasonal WCI patterns and the spatially averaged time series revealed that the weekly variability of $\mathrm{AOD}_{550}$ over Europe is driven by the summer weekly patterns. The general pattern with the strong positive weekly cycle over CE and the strong negative weekly cycle over SWE and NEE is even clearer during summer. The region with the most stable weekly variability throughout a year is CE with a clear midweek maximum and a weekend minimum. In the case of SWE and NEE the idea of midweek minima and weekend maxima is preserved; however, the weekly variability is generally differentiated throughout a year. In general, CM, EM and CEE exhibit different weekly variability for different seasons. Air masses arriving from regions with strong and clear weekly cycles (e.g. CE) may be critical for the aerosol weekly cycles over regions away from human activities or regions with a weak aerosol weekly variability. The seasonal MODIS AOD 550 weekly patterns were used in conjunction with NCEP/NCAR reanalysis 850 mbar pressure level wind speed and wind direction, in order to show that the seasonal weekly cycle plumes over regions situated in the eastern Europe and the Mediterranean Sea, could be partly attributed to the westerly transport of continental aerosols from the dominating synoptic wind patterns.

\section{Supplementary material related to this article is available online at: http://www.atmos-chem-phys.net/11/4611/2011/ acp-11-4611-2011-supplement.zip.}

Acknowledgements. The authors would like to thank NASA Goddard Space Flight Center (GSFC) Level 1 and Atmosphere Archive and Distribution System (LAADS) (http://ladsweb.nascom.nasa.gov) for making available the MODIS TERRA and AQUA C005 Level 3 aerosol data and the NOAA/OAR/ESRL PSD, Boulder, Colorado, USA for providing the NCEP/NCAR reanalysis wind data (http://www.esrl.noaa.gov/psd).

Edited by: J. Quaas

\section{References}

Altshuler, S. L., Arcado, T. D., and Lawson, D. R.: Weekday vs. weekend ambient ozone concentrations: discussion and hypotheses with focus on northern California, J. Air Waste Manage., 45, 967-972, 1995.

Ashworth, J. R.: The influence of smoke and hot gases from factory chimneys on rainfall, Q. J. Roy. Meteor. Soc., 55, 341-350, 1929.

Ashworth, J. R.: Rainfall and atmospheric pollution, Nature, 132, p. $443,1933$.

Barmet, P., Kuster, T., Muhlbauer, A., and Lohmann, U.: Weekly cycle in particulate matter versus weekly cycle in precipitation over Switzerland, J. Geophys. Res., 114, D05206, doi:10.1029/2008JD011192, 2009.

Barnaba, F. and Gobbi, G. P.: Aerosol seasonal variability over the Mediterranean region and relative impact of maritime, continental and Saharan dust particles over the basin from MODIS data in the year 2001, Atmos. Chem. Phys., 4, 2367-2391, doi:10.5194/acp-4-2367-2004, 2004.

Bäumer, D. and Vogel, B.: An unexpected pattern of distinct weekly periodicities in climatological variables in Germany, Geophys. Res. Lett., 34, L03819, doi:10.1029/2006GL028559, 2007.

Bäumer, D. and Vogel, B.: Reply to comment by H. J. Hendricks Franssen on "An unexpected pattern of distinct weekly 
periodicities in climatological variables in Germany", Geophys. Res. Lett., 35, L05803, doi:10.1029/2007GL032432, 2008.

Bäumer, D., Rinke, R., and Vogel, B.: Weekly periodicities of Aerosol Optical Thickness over Central Europe - evidence of an anthropogenic direct aerosol effect, Atmos. Chem. Phys., 8, 8390, doi:10.5194/acp-8-83-2008, 2008.

Beirle, S., Platt, U., Wenig, M., and Wagner, T.: Weekly cycle of $\mathrm{NO}_{2}$ by GOME measurements: a signature of anthropogenic sources, Atmos. Chem. Phys., 3, 2225-2232, doi:10.5194/acp-32225-2003, 2003.

Bell, T. L., Rosenfeld, D., Kim, K.-M., Yoo, J.-M., Lee, M.-I., and Hahnenberger, M.: Midweek increase in US summer rain and storm heights suggests air pollution invigorates rainstorms, J. Geophys. Res., 113, D02209, doi:10.1029/2007JD008623, 2008.

Bower, J. S., Broughton, G. F., Dando, M. T., Stevenson, K. J., Lampert, J. E., Sweeney, B. P., Parker, V. J., Driver, G. S., Clark, A. G., Waddon, C. J., Wood, A. J., and Williams, M. L.: Surface ozone concentrations in the UK in 1987-1988, Atmos. Environ., 23, 2003-2016, 1989.

Brönnimann, S. and Neu, U.: Weekend-weekday differences of near-surface ozone concentrations for different meteorological conditions, Atmos. Environ., 31, 1127-1135, 1997.

Cerveny, R. S. and Balling Jr., R. C.: Weekly cycles of air pollution, precipitation and tropical cyclones in the coastal NW Atlantic region, Nature, 394, 561-563, 1998.

Choi, Y.-S., Ho, C.-H., Chen, D., Noh, Y.-H., and Song, C.-K.: Spectral analysis of weekly variation in $\mathrm{PM}_{10}$ mass concentration and meteorological conditions over China, Atmos. Environ., 42, 655-666, 2008.

Chu, D. A., Kaufman, Y. J., Ichoku, C., Remer, L. A., Tanré, D., and Holben, B. N.: Validation of MODIS aerosol optical depth retrieval over land, Geophys. Res. Lett., 29, 8007, doi:10.1029/2001GL013205, 2002.

Cleveland, W. S. and McRae, J. E.: Weekday-weekend ozone concentrations in the Northeast United States, Environ. Sci. Technol., 12, 558-563, 1978.

Cleveland, W. S., Graedel, T. E., Kleiner, B., and Warner, J. L.: Sunday and workday variations in photochemical air pollutants in New Jersey and New York, Science, 186, 1037-1038, 1974.

DeLisi, M. P., Cope, A. M., and Franklin, J. K.: Weekly precipitation cycles along the northeast corridor?, Weather Forecast., 16, 343-353, 2001.

Elkus, B. and Wilson, K. R.: Photochemical air pollution: Weekend-weekday differences, Atmos. Environ., 11, 509-515, 1977.

Forster, P. M. and Solomon, S.: Observations of a "weekend effect” in diurnal temperature range, P. Natl. Acad. Sci. USA, 100, 11225-11230, 2003.

Ghil, M., Allen, M. R., Dettinger, M. D., Ide, K., Kondrashov, D., Mann, M. E., Robertson, A.W., Saunders, A., Tian, Y., Varadi, F., and Yiou, P.: Advanced spectral methods for climatic time series, Rev. Geophys., 40(1), 1003, doi:10.1029/2000RG000092, 2002.

Gkikas, A., Hatzianastassiou, N., and Mihalopoulos, N.: Aerosol events in the broader Mediterranean basin based on 7-year (2000-2007) MODIS C005 data, Ann. Geophys., 27, 35093522, doi:10.5194/angeo-27-3509-2009, 2009.

Gong, D., Ho, C., Chen, D., Qian, Y., Choi, Y., and Kim, J.: Weekly cycle of aerosol-meteorology interaction over China, J. Geophys. Res., 112, D22202, doi:10.1029/2007JD008888, 2007.
Gordon, A. H.: Weekdays warmer than weekends?, Nature, 367, 325-326, 1994.

Haagen-Smit, A. and Brunelle, M. F.: The application of phenolphthalin reagent to atmospheric oxidant analysis, Int. J. Air Poll., 1, 51-59, 1958.

Hendricks Franssen, H.: Comment on "An unexpected pattern of distinct weekly periodicities in climatological variables in Germany" by Dominique Bäumer and Bernhard Vogel, Geophys. Res. Lett., 35, L05802, doi:10.1029/2007GL031279, 2008.

Hendricks Franssen, H. J., Kuster, T., Barmet, P., and Lohmann, U.: Comment on "Winter "weekend effect" in southern Europe and its connection with periodicities in atmospheric dynamics" by A. Sanchez-Lorenzo et al., Geophys. Res. Lett., 36, L13706, doi:10.1029/2008GL036774, 2009.

Heuss, J. M., Kahlbaum, D. F., and Wolff, G.T.: Weekday/weekend ozone differences: what can we learn from them?, J. Air Waste Manage., 53(7), 772-788, 2003.

Hies, T., Treffeisen, R., Sebald, L., and Reimer, E.: Spectral analysis of air pollutants. Part 1: elemental carbon time series, Atmos. Environ., 34, 3495-3502, 2000.

Jin, M., Shepherd, J. M., and King, M. D.: Urban aerosols and their variations with clouds and rainfall: A case study for New York and Houston, J. Geophys. Res., 110, D10S20, doi:10.1029/2004JD005081, 2005.

Kalivitis, N., Gerasopoulos, E., Vrekoussis, M., Kouvarakis, G., Kubilay, N., Hatzianastassiou, N., Vardavas, I., and Mihalopoulos, N.: Dust transport over the eastern Mediterranean derived from TOMS, AERONET and surface measurements, J. Geophys. Res., 112, D03202, doi:10.1029/2006JD007510, 2007.

Kalnay, E., Kanamitsu, M., Kistler, R., Collins, W., Deaven, D., Gandin, L., Iredell, M., Saha, S., White, G., Woollen, J., Zhu, Y., Leetmaa, A., Reynolds, B., Chelliah, M., Ebisuzaki, W., Higgins, W., Janowiak, J., Mo, K. C., Ropelewski, C., Wang, J., Jenne, R., and Joseph, D.: The NCEP/NCAR 40-Year Reanalysis Project, B. Am. Meteorol. Soc., 77, 437-472, 1996.

Karl, T. R.: Day of the week variations of photochemical pollutants in the St. Louis area, Atmos. Environ., 12, 1657-1667, 1978.

Kaskaoutis, D. G., Kosmopoulos, P., Kambezidis, H. D., and Nastos, P. T.: Aerosol climatology and discrimination of different types over Athens, Greece, based on MODIS data, Atmos. Environ., 41(34), 7315-7329, 2007.

Kaufman, Y. J., Tanré, D., Remer, L. A., Vermote, E. F., Chu, A., and Holben, B. N.: Operational remote sensing of tropospheric aerosol over land from EOS moderate resolution imaging spectroradiometer, J. Geophys. Res., 102, 17051-17065, 1997.

Kim, B.-G., Choi, M.-H., and Ho, C.-H.: Weekly periodicities of meteorological variables and their possible association with aerosols in Korea, Atmos. Environ., 43(38), 6058-6065, doi:10.1016/j.atmosenv.2009.08.023, 2009.

Kim, K.-Y., Park R. J., Kim K.-R., and Na, H.: Weekend effect: Anthropogenic or natural?, Geophys. Res. Lett., 37, L09808, doi:10.1029/2010GL043233, 2010.

Kistler, R., Kalnay, E., Collins, W., Saha, S., White, G., Woollen, J., Chelliah, M., Ebisuzaki, W., Kanamitsu, M., Kousky, V., van den Dool, H., Jenne, R., and Fiorino, M.: The NCEP-NCAR 50year reanalysis: Monthly means CD-ROM and documentation, B. Am. Meteorol. Soc., 82, 247-267, 2001.

Laux, P. and Kunstmann, H.: Detection of regional weekly weather cycles across Europe, Environ. Res. Lett., 3, 044005, 
doi:10.1088/1748-9326/3/4/044005, 2008.

Lebron, F.: A comparison of weekend-weekday ozone and hydrocarbon concentrations in the Baltimore-Washington metropolitan area, Atmos. Environ., 9, 861-863, 1975.

Levy, R. C., Remer, L. A., Tanré, D., Kaufman, Y. J., Ichoku, C., Holben, B. N., Livingston, J. M., Russell, P. B., and Maring, H.: Evaluation of the Moderate-Resolution Imaging Spectroradiometer (MODIS) retrievals of dust aerosol over the ocean during PRIDE, J. Geophys. Res., 108(D19), 8594, doi:10.1029/2002JD002460, 2003.

Levy, R., Remer, L., and Dubovik, O.: Global aerosol optical properties and application to moderate resolution imaging spectroradiometer aerosol retrieval over land, J. Geophys. Res., 112, D13210, doi:10.1029/2006JD007815, 2007a.

Levy, R. C., Remer, L. A., Mattoo, S., Vermote, E. F., and Kaufman, Y. J.: Second-generation operational algorithm: Retrieval of aerosol properties over land from inversion of moderate resolution imaging spectroradiometer spectral reflectance, J. Geophys. Res., 112, D13211, doi:10.1029/2006JD007811, 2007b.

Levy, R., Remer, L., Tanré, D., Mattoo, S., and Kaufman, Y.: Algorithm for remote sensing of tropospheric aerosol over dark targets from MODIS: Collections 005 and 051: Revision 2, February 2009, MODIS Algorithm Theoretical Basis Document, 2009.

Levy, R. C., Remer, L. A., Kleidman, R. G., Mattoo, S., Ichoku, C., Kahn, R., and Eck, T. F.: Global evaluation of the Collection 5 MODIS dark-target aerosol products over land, Atmos. Chem. Phys., 10, 10399-10420, doi:10.5194/acp-10-10399-2010, 2010.

Lonneman, W. A., Kopczynski, S. L., Darley, P. E., and Sutterfield, F. D.: Hydrocarbon composition of urban air pollution, Environ. Sci. Technol., 8, 229-236, 1974.

Mann, M. E. and Lees, J. M.: Robust estimation of background noise and signal detection in climatic time series, Clim. Change, 33(3), 409-445, 1996.

Marr, L. C. and Harley, R. A., Spectral analysis of weekdayweekend differences in ambient ozone, nitrogen oxide, and nonmethane hydrocarbon time series in California, Atmos. Environ., 36, 2327-2335, 2002.

Meloni, D., di Sarra, A., Biavati, G., DeLuisi, J. J., Monteleone F., Pace, G., Piacentino, S., and Sferlazzo, D. M.: Seasonal behavior of Saharan dust events at the Mediterranean island of Lampedusa in the period 1999-2005, Atmos. Environ., 41, 3041-3056, 2007.

Murphy, J. G., Day, D. A., Cleary, P. A., Wooldridge, P. J., Millet, D. B., Goldstein, A. H., and Cohen, R. C.: The weekend effect within and downwind of Sacramento - Part 1: Observations of ozone, nitrogen oxides, and VOC reactivity, Atmos. Chem. Phys., 7, 5327-5339, doi:10.5194/acp-7-5327-2007, 2007.

Murphy, D. M., Capps, S. L., Daniel, J. S., Frost, G. J., and White, W. H.: Weekly patterns of aerosol in the United States, Atmos. Chem. Phys., 8, 2729-2739, doi:10.5194/acp-8-2729-2008, 2008.

Papayannis, A., Balis, D., Amiridis, V., Chourdakis, G., Tsaknakis, G., Zerefos, C., Castanho, A. D. A., Nickovic, S., Kazadzis, S., and Grabowski, J.: Measurements of Saharan dust aerosols over the Eastern Mediterranean using elastic backscatter-Raman lidar, spectrophotometric and satellite observations in the frame of the EARLINET project, Atmos. Chem. Phys., 5, 2065-2079, doi:10.5194/acp-5-2065-2005, 2005.

Paschalidou, A. K. and Kassomenos, P. A.: Comparison of air pollutant concentrations between weekdays and weekends in
Athens, Greece for various meteorological conditions, Environ. Technol., 25(11), 1241-1255, 2004.

Percival, D. B. and Walden, A. T.: Spectral analysis for physical applications. Multitaper and conventional univariate techniques, Cambridge University Press, Cambridge, 612 pp., 1993.

Pont, V. and Fontan, J.: Comparison between weekend and weekday ozone concentrations in large cities in France, Atmos. Environ., 35, 1527-1535, 2001.

Priestley, M. B.: Spectral analysis and time series, Academic Press, London, 890 pp., 1981.

Pryor, S. C. and Steyn, D. G.: Hebdomadal and diurnal cycles in ozone time series from the Lower Fraser Valley, BC, Atmos. Environ., 29, 1007-1019, 1995.

Quaas, J., Boucher, O., Jones, A., Weedon, G. P., Kieser, J., and Joos, H.: Exploiting the weekly cycle as observed over Europe to analyse aerosol indirect effects in two climate models, Atmos. Chem. Phys., 9, 8493-8501, doi:10.5194/acp-9-8493-2009, 2009.

Remer, L. A., Tanré, D., Kaufman, Y. J., Ichoku, C., Mattoo, S., Levy, R., Chu, D. A., Holben, B., Dubovik, O., Smirnov, A., Martins, J. V., Li, R.-R., and Ahman, Z.: Validation of MODIS aerosol retrieval over ocean, Geophys. Res. Lett., 29(12), 8008, doi:10.1029/2001/GL013204, 2002.

Remer, L., Kaufman, Y., Tanre, D., Mattoo, S., Chu, D., Martins, J., Li, R.-R., Ichoku, C., Levy, R. C., Kleidman, R. G., Eck, T. F., Vermote, E., Holben, B. N.: The MODIS aerosol algorithm, products, and validation, J. Atmos. Sci., 62(4), 947-973, 2005.

Remer, L. A., Tanré, D., Kaufman, Y. J., Levy, R., and Mattoo, S.: Algorithm for remote sensing of Tropospheric aerosol from MODIS: Collection 5, Product ID: MOD04/MYD04, 2006.

Rosenfeld, D., Lohmann, U., Raga, G. B., O’Dowd, C. D., Kulmala, M., Fuzzi, S., Reissell, A., and Andreae, M. O.: Flood or drought: How do aerosols affect precipitation?, Science, 321(5894), 1309-1313, doi:10.1126/science.1160606, 2008.

Sanchez-Lorenzo, A., Calbó, J., Martin-Vide, J., Garcia-Manuel, A., García-Soriano, G., and Beck, C.: Winter "weekend effect" in southern Europe and its connections with periodicities in atmospheric dynamics, Geophys. Res. Lett., 35, L15711, doi:10.1029/2008GL034160, 2008.

Sanchez-Lorenzo, A., Calbó, J., and Martin-Vide, J.: Reply to comment by H. J. Hendricks Franssen et al. on "Winter "weekend effect' in southern Europe and its connections with periodicities in atmospheric dynamics", Geophys. Res. Lett., 36, L13707, doi:10.1029/2009GL038041, 2009.

Schipa, I., Tanzarella, A., and Mangia, C.: Differences between weekend and weekday ozone levels over rural and urban sites in Southern Italy, Environ. Monit. Assess., 156, 509-523, 2009.

Schultz, D. M., Mikkonen, S., Laaksonen, A., and Richman, M. B.: Weekly precipitation cycles?, Lack of evidence from United States surface stations, Geophys. Res. Lett., 34, L22815, doi:10.1029/2007GL031889, 2007.

Shutters, S. T. and Balling Jr., R. C.: Weekly periodicity of environmental variables in Phoenix, Arizona, Atmos. Environ., 40, 304-310, 2006.

Simmonds, I. and Keay, K.: Weekly cycle of meteorological variations in Melbourne and the role of pollution and anthropogenic heat release, Atmos. Environ., 31, 1589-1603, 1997.

Sitnov, S. A.: Weekly cycle of meteorological parameters over Moscow region, Dokl. Earth Sci., 431(2), 507-513, 2010. 
Stephens, S., Madronich, S., Wu, F., Olson, J. B., Ramos, R., Retama, A., and Muñoz, R.: Weekly patterns of México City's surface concentrations of $\mathrm{CO}, \mathrm{NO}_{\mathrm{x}}, \mathrm{PM}_{10}$ and $\mathrm{O}_{3}$ during 19862007, Atmos. Chem. Phys., 8, 5313-5325, doi:10.5194/acp-85313-2008, 2008.

Tafuro, A. M., Barnaba, F., de Tomasi, F., Perrone, M. R., and Gobbi, G. P.: Saharan dust particles properties over the central Mediterranean, Atmos. Res., 81, 67-93, 2006.

Tanré, D., Kaufman, Y. J., Herman, M., and Mattoo, S.: Remote sensing of aerosol properties over oceans using the MODIS/EOS spectral radiances, J. Geophys. Res., 102, 16971-16988, 1997.

Toledano, C., Cachorro, V. E., de Frutos, A. M., Sorribas, M., Prats, N., and de la Morena, B. A.: Inventory of African desert dust events over the south-western Iberian Peninsula in 2000-2005 with an AERONET Cimel Sun photometer, J. Geophys. Res., 112, D21201, doi:10.1029/2006JD008307, 2007.
Vukovich, F. M.: The spatial variation of the weekday/weekend differences in the Baltimore area, J. Air Waste Manage., 50, 20672072, 2000.

Weedon, G. P.: Time series analysis and cyclostratigraphy: Examining stratigraphic records of environmental cycles, Cambridge University Press, New York, 276 pp., 2005.

Wilks, D. S.: Statistical methods in the atmospheric sciences, 2nd Ed. International Geophysics Series vol. 59, Academic Press, San Diego, 627 pp., 2006.

Xia, X., Eck, T. F., Holben, B. N., Phillippe, G., and Chen, H.: Analysis of the weekly cycle of aerosol optical depth using AERONET and MODIS data, J. Geophys. Res., 113, D14217, doi:10.1029/2007JD009604, 2008. 